\title{
Metastability at Defective Metal Oxide Interfaces and Nanoconfined Structures
}

\author{
Esposito, Vincenzo; Castelli, Ivano Eligio
}

Published in:

Advanced Materials Interfaces

Link to article, DOI:

10.1002/admi.201902090

Publication date:

2020

Document Version

Peer reviewed version

Link back to DTU Orbit

Citation (APA):

Esposito, V., \& Castelli, I. E. (2020). Metastability at Defective Metal Oxide Interfaces and Nanoconfined Structures. Advanced Materials Interfaces, 7(13), [1902090]. https://doi.org/10.1002/admi.201902090

\section{General rights}

Copyright and moral rights for the publications made accessible in the public portal are retained by the authors and/or other copyright owners and it is a condition of accessing publications that users recognise and abide by the legal requirements associated with these rights.

- Users may download and print one copy of any publication from the public portal for the purpose of private study or research.

- You may not further distribute the material or use it for any profit-making activity or commercial gain

- You may freely distribute the URL identifying the publication in the public portal

If you believe that this document breaches copyright please contact us providing details, and we will remove access to the work immediately and investigate your claim. 
DOI: $10.1002 /$ admi.201901219

\section{Review}

\section{Metastability at defective metal oxide interfaces and nanoconfined structures}

Prof Vincenzo Esposito ${ }^{1}$ and Asst. Prof. Ivano E. Castelli ${ }^{1}$

${ }^{1}$ Department of Energy Conversion and Storage, Technical University of Denmark, DK-2800 kgs. Lyngby, Denmark

E-mail: vies@dtu.dk (VE)

Keywords: Nanostructures, Nanoparticles, Metal oxides, Interface, Surface, Metastability, Defects, Ionics

Most of the paradigms in materials science and technology firmly rely on equilibrium materials, i.e., phases with the lowest Gibbs energy under thermodynamic conditions. In nature, however, complexity rules, and the other aspect is metastability. This review paper aims to provide a coherent description of such effects and to formulate hypotheses on the fundamental energetic mechanisms of residual metastability in crystalline metal oxide polymorphs. We especially focus on different forms of broken symmetry at the interface, e.g., induced by defects, lattice strain/stress, and elemental diffusion. The discussion also provides perspective on the technological implications and possibilities arising from identifying a general methodology for establishing metastability in polymorphic functional metal oxides for energy applications, catalysis, and electronics.

\section{Introduction}

Thermodynamically stable phases, or "Gibbs phases", are generally defined as phases that are globally stable with respect to their Gibbs free energy, i.e., the lowest energy. Gibbs phases are persistent and reliable, and their properties are usually those expected based on their chemistry. These phases often refer to unitary and ideally infinite structures with homogeneous bulk composition. In a wider definition, a compound is stable if it is synthetically accessible and it does not separate into competing phases. 
Conversely, metastable phases lay outside the thermodynamical conditions and can coexist with other phases, e.g. in form of polymorphism. Metastability often arises from rapid changes at their environment that can trap energetic excitement randomly dependent on kinetics transformations or other external factors. This special status makes them accidental and ubiquitous and often leads to superior properties or to energetic mechanisms that translate into advanced functionalities applicable in mechanics, electronics, catalysis, batteries, and medicine, among others ${ }^{[1-5]}{ }^{[6-9]}$. The discovery of metastable materials and their synthesis procedure is thus one route towards promising novel functional materials and discovery.

The interface plays a primary and rather complex role in the configuration of material energetics. Kinetically, the interface is "the gate" for the material's transformation, where the external conditions initially affects the material and where the boundary conditions of the transformation are established. At the surface of crystalline metal oxides, such processes occur by spontaneous redox reactions of metals with oxygen gas, moisture, external volatile and liquid chemicals, or by oxidative/reducing species present in the environment. These can locally alter the energetic pathway and subtly direct the kinetic mechanisms towards alternative energetic configurations from the thermodynamics. In other cases, the interface is built-in, e.g., in the nanometric range for solid-solid interfaces. Here, metastability takes place between nanocrystals at the grain boundaries or between different phases in nanocomposites and heterostructures. For such systems, the bulk is often a minor component, and interfaces dominate the overall material properties. Such interface-based oxides exhibit a large variety of tuneable functionalities, providing the foundation for a new generation of nanoengineered materials and devices. ${ }^{[10-13]}$ Although materials nanoengineering is currently extensively adopted for functional oxides ${ }^{[14]}$, energetic imprinting via metastability is still an unexplored matter in the material science. Imprinting metastability at the interface is however possible. As an illustrative example, we here refer to materials that can build metastability though polymorphic transformations: Figure 1 presents a possible energetic pathway for imprinting 
interface-based metastable phases, where the interface energy, e.g., the energy introduced by structural factors during the transformation can locally modify the formation of the Gibbs $\beta$ phase and other metastable polymorphs. This can occur by kinetically trapping the already existing "remnant $\alpha$-phase"; i.e., the phase transformation from the metastable $\alpha$-phase to the Gibbs $\beta$-phase is suppressed ${ }^{[15]}$. The interface can thus contribute in such transformations supplying additional energetic contributions. One can question that the kinetics at the interface can be indeed uncertain and polymorphic materials can generate a plethora of structures that are energetically indistinguishable. However, the remnant metastability case indicates that scenario in materials science is rapidly changing. ${ }^{[16]}$ For metastability in polymorphic crystalline materials, big data analysis based on experimental and theoretical data on metastable phases has recently been capable of providing an analytical answer to questions related, indicating, e.g., that not all metastable phases are actually obtainable. ${ }^{[15,17]}$ It also appears clear that there is a connection between the pristine phase and its evolution into a metastable form, i.e., remnant metastability ${ }^{[15]}$ and there even are a few examples where a stabilization of metastable polymorphs has been achieved thanks to the interface ${ }^{[18-23]}$.

The use modern computational tools together with the development of advanced synthesis methods allows atomic-scale control of the material and the question is: are we approaching the point where we can study metastability at interfaces in a high-throughput fashion?

Some robust examples are already registered in the combinatorial synthesis methods non-interface based materials ${ }^{[24]}$ and in the development of artificial intelligence/machine learning models of bulk compounds ${ }^{[25]}$. These two new methods already have the potential to rationalize, predict and synthesize metastability at interfaces, e.g. building effective models and methodologies for functional material in energy storage, electronic and catalysis ${ }^{[10,26,27]}$. For interface-based metastable oxides, experimental work mainly includes renowned examples of single metal oxides such as titanium oxide, zirconium oxide, vanadium oxide, manganese oxide, 
iron oxide, and zinc oxide nanomaterials ${ }^{[18-23]}$. All these metal oxides have in common that exhibit a large variety of phases, i.e., high-density polymorphism, often with different properties. The use modern computational tools already cover polymorphic materials and novel experimental methods seem ready to address scientific questions about metastability and interfaces.

This review paper aims such a scenario by providing a coherent description of possible energetic mechanisms leading to residual metastability in crystalline metal oxide with highdensity polymorphism. These are polymorphic materials with a large number of stable polymorphs. Such phases can require either high- or low-energy difference to transform form one to another (Figure 2). We use here both experimental evidence, reported in the wide literature on the topic, as well as from a theoretical viewpoint, mostly at the atomistic level. Due to the extension and specificity of certain topics, we have limited the discussion to include the recurrent elements found in the literature only and to very few selected metal oxides. In the last part of the paper, we attempt to provide a perspective on possible "paths towards metastability through interfaces" for some metal oxides with relevance to various technological applications.

For the organization of the manuscript, the discussion is structured as follows:

- Section 2 reports the advances in the computational tools used to model metal oxides and their interfaces, with a focus on investigating polymorphic structures and energetics;

- Section 3 addresses the most recent experimental discoveries of pathways that can stabilize metastable structures through external factors, such as nanoparticle size, cation diffusion, defects, and strain, and the role of the interface;

- Section 4 is a perspective addressing possible design criteria to stabilize metastable polymorphs through strain, defects, and cation diffusion. 


\section{WILEY-VCH}

\section{Metal oxide interface energetics: computational tools}

Materials design by means of simulations, often in the framework of density functional theory (DFT) ${ }^{[28]}$, has become increasingly popular and accurate thanks both to improvements in the methodologies and in the computational power ${ }^{[29]}$. At the atomistic level, we are now able to simulate systems form up to several hundreds of atoms, from the simplest bulk materials to complex electrochemical (solid/liquid) and solid/solid interfaces.

\subsection{Modelling of bulk materials and polymorphs}

Because of the relatively small computational cost and of their nature of building blocks, bulk materials are the most common systems studied computationally. Stability is a key point in the investigation of energetics relation between known structures and for the in-silico design of novel materials. The most popular descriptor ${ }^{[30]}$ for stability is the so-called convex hull, which defines the stability frontier by comparing the energies of all the possible materials and phases at a given chemical space. These phases can both come from experimental databases, i.e., their synthesis path is known, such as ICSD ${ }^{[31]}$, Springer Materials ${ }^{[32]}$, and HTEM $^{[33]}$, or computational repositories, which could cover both known and unknown, i.e., computationally designed and not synthesized yet, materials (Materials Project ${ }^{[34]}$, OQMD ${ }^{[35]}$, AflowLib [36], Materials Cloud ${ }^{[37]}$, NREL ${ }^{[38]}$, and CMR ${ }^{[39]}$ ). These databases, beyond collecting, among others, structural, electronic, catalytic data, can provide the plethora of different phases for a given chemical composition. The polymorphs of a few significant binary oxides mentioned in this work are reported in Figure 2. As an example, titanium dioxide $\left(\mathrm{TiO}_{2}\right.$ or titania) can be found in nature in crystal structures, such as rutile, anatase, or brookite, or it is synthesized under high pressure in the hollandite, columbite, or ramsdellite structures ${ }^{[40]}$. All of these differ in energy by less than $70 \mathrm{meV} / \mathrm{atom}$, but we can find other phases at much higher energies. Because of their different structures, polymorphs often show significant differences also in their properties (Figure 2 reports the DFT calculated band gaps for the considered 


\section{WILEY-VCH}

polymorphs). Polymorphs can thus be used for different applications. Since its discovery as a material able to split water into hydrogen and oxygen ${ }^{[41,42]}$, the anatase, brookite and rutile of titania have very similar band gaps, their catalytic properties are different and anatase shows the highest efficiency for photoelectrochemical activity ${ }^{[43]}$. Comprehensive studies have been conducted to identify and assess metastability in polymorphs and their synthesizability [15]. As a rule of thumb, there is a high likelihood of a polymorph being synthesizable when its energy is up to $70 \mathrm{meV} /$ atom above the ground state energy, although it has been possible to synthesize polymorphs with an energy approximately $200 \mathrm{meV} /$ atom above the ground state energy [13]. In Figure 2, we can identify two regimes of polymorphism: (i) structures with a small energy difference for phase transformation (<10 meV/atom) and (ii) structures where the energy difference is significantly larger. In regime (i), small changes in the external conditions might have a catastrophic effect on the stability of the polymorph and it might be easier to explore the various polymorphs. This phenomenon should not happen in regime (ii), in which the metastability is more robust and more intense factors are needed to escape from the local minimum and explore different polymorphisms. For instance, the cotunnite, columbite, and rutile phases of $\mathrm{TiO}_{2}$ have rather similar energies and belong to regime (i). On the other side, $\mathrm{V}_{2} \mathrm{O}_{5}$ and $\mathrm{Bi}_{2} \mathrm{O}_{3}$ belong to regime (ii) as its $\alpha$-, $\beta$-, $\gamma$-, and $\delta$-phases have wider energy difference of $20 \mathrm{meV} / \mathrm{atom}$ and more (see Figure 2). There are then materials, such as $\mathrm{Fe}_{2} \mathrm{O}_{3}$, where the two regimes coexist, i.e., with a large energy difference between the haematite and $\varepsilon$ orthorhombic phases and minimal energy difference between the $\varepsilon$-orthorhombic and bixbyite phases. From a technical point of view, calculating these (small) energy differences might be tricky using standard DFT within the generalized gradient approximation of Perdew, Burke and Ernzerhof (GGA-PBE ${ }^{[44]}$ ), and the wrong ground state might be identified, as pointed out for $\mathrm{TiO}_{2}{ }^{[45]}$. This issue has been partially solved using more accurate methods and exchangecorrelation functionals, including DFT+U ${ }^{[46]}$, HSE06 ${ }^{[47]}, \mathrm{SCAN}^{[48]}$, BEEF-vdW ${ }^{[49]}$, etc. ${ }^{[50]}$. 
Both thermodynamics and kinetics play a role in understanding the metastability of materials. Thermodynamically, this analysis is strongly related with the problem of finding the ground state structure for a given composition. Multiple techniques have been developed for this purpose, including genetic/evolutionary algorithms ${ }^{[51,52]}$, structural prototypes ${ }^{[53]}$, random structure searching ${ }^{[54]}$, superlattices ${ }^{[55]}$, simulated annealing ${ }^{[56]}$, meta-dynamics ${ }^{[57,58]}$, basin and minima hopping ${ }^{[59,60]}$, data mining and artificial intelligence ${ }^{[61]}$. On the other side, kinetics aspects are much more computationally demanding to investigate and synthesis conditions are often not included in the calculations, e.g., standard DFT calculates the material properties at 0 K. A computational prediction of a metastability pathway, which depends on synthesis conditions, is thus extremely challenging, and the synthesis of metastable polymorphs is still a matter of experience and "trial and error". Recent works have demonstrated that this prediction is, however, possible. Two examples are a methodology based on only crystallographic arguments to understand the diffusionless polymorphic transformations of $\mathrm{SnO}_{2}{ }^{[62]}$ and the use of artificial intelligence to assess the temperature dependence of metastability ${ }^{[63]}$ and to include factors such as kinetics, synthesis techniques, and availability of precursors, for the synthesizability of novel materials beyond thermodynamic considerations ${ }^{[64]}$. In addition, most of the computational work is performed for perfect crystals, e.g. single crystals, non-defective materials. This is of course far from the real experimental cases, where defective, polycrystalline, and even amorphous, materials are synthesized. Although more computationally demanding than the pure case, defective calculations are now standards in DFT. For point defects, these calculations are relatively simple and they rely on the creation of a supercell with and without defects and compare their energetics with the defect in its standard state. For charged defects the analysis is a more complex as the energy of the defect depends on the electronic properties (Fermi level) of the host. These factors are generally underestimated in DFT and are related with the definition of the chemical potential of the defect, and by the supercell approximation, which considers a periodic repetition of defects, rather than a single 
one isolated ${ }^{[65]}$. Different models have been suggested to overcome these issues ${ }^{[65-67]}$. After decades of tedious, manual work on defects for specific materials, recently, python toolkits have been implemented to automate and accelerate the investigation of defects in a high-throughput way ${ }^{[68,69]}$. Polycrystallinity is a property of the interface, which is treated in the next section. DFT can be used to model grain boundaries, dislocations, and polycrystalline interfaces, however, the number of atoms needed to be simulated is significantly increased from the pure bulk case and interatomic potentials might become more appropriate, as shown for $\mathrm{TiO}_{2}{ }^{[70-72]}$. Empirical models ${ }^{[73]}$ as well as post-DFT methods ${ }^{[74]}$, which combine DFT with lattice Green function using flexible boundary conditions, have been used in different contexts to study grain boundaries and dislocations. DFT alone cannot reproduce the complex structure of an amorphous compound, but it can be combined with Molecular Dynamics (MD) or classical interatomic potentials (CIP) to generate an ensemble of model structures, which can be used to extrapolate the properties of amorphous crystals, as it has been done for $\mathbf{T i O}_{2}, \mathbf{A l}_{\mathbf{2}} \mathbf{O}_{\mathbf{3}}$, and $\mathrm{ZrO}_{2}$, to mention a few cases ${ }^{[75-77]}$. Most of the abovementioned studies and methods are used in an Edisonian way to explain physico-chemical properties of materials, rather than to design a pathway for metastability.

\subsection{Modelling metastability at the interfaces}

Understanding the role of the interfaces is crucial for many reasons, from the application of the materials in devices to investigate, more fundamentally, their structural and chemical properties. Computationally, surfaces are more difficult to treat compare to bulk systems: in addition to multiple polymorphs, they often show multiple (meta)stable terminations and from, the technical point, the structures to simulate have many more atoms than the primitive cell used in bulk calculations. For these and other reasons, often the interface problems are simplified by considering only bulk energies and structures, thus ignoring the interface contributions. An example of multiple metastable termination is $\mathrm{SrTiO}_{3}$ : the n-type termination 
$\left(\mathrm{TiO}_{2}\right)$ is conductive, while the p-type $(\mathrm{SrO})$ is insulating. This gives rise to a variety of different phenomena and applications that can be developed as a function of the considered termination. ${ }^{[78]}$ Atomistic models ${ }^{[79,80]}$ have been implemented to assist with the identification of most stable surfaces in different electrochemical conditions ${ }^{[81]}$ or oxygen partial pressure. ${ }^{[82]}$ When electronic properties are strongly coupled to the system's energetics, these models can, however, give faulty results due to the well-known challenges in DFT for calculating the electronics properties. ${ }^{[83]}$

Additionally, there are cases where the stabilization of metastable structures and interfaces is linked with the electrochemical environment, as demonstrated for $\mathrm{BaTiO}_{3}$, for which the bare surfaces have been calculated unstable. ${ }^{[84]}$ In the most simple way, computational Pourbaix diagrams can be constructed to estimate the electrochemical stability ${ }^{[85-87]}$ and metastability ${ }^{\text {[88] }}$ of the solid/liquid(water) interface at the atomistic and bulk level and to design novel materials ${ }^{[89-91]}$. This methodology combines computational (bulk) information on solid phases (total energies) and experimental data for dissolved species (dissolution energies). More accurate results can be obtained by modelling the interface with explicit or implicit solvents ${ }^{[92]}$. This methods come at a significant increase of the computational cost and currently cannot be performed in a high-throughput way. DFT can also provide input data used by ab initio thermodynamics models to study nucleation rate or phase selectivity, in a similar way as is has been done for the nucleation of aragonite instead of calcite in seawater and the growth of $\mathrm{FeS}_{2}$ polymorphs in water. ${ }^{[93,94]}$

Multiple examples can be found in the literature regarding the computational studies of the solid/solid interface. With respect to metastability and polymorphism, various techniques have allowed identifying combinations of substrate/polymorphs that could achieve a stabilization of metastable structures: stabilization of transition metal dioxide $\left(\mathrm{MeO}_{2}\right)$ polymorphs through epitaxial growth is possible when the (bulk) energy of the polymorph is within $200 \mathrm{meV} /$ atom from the ground state energy ${ }^{[95]}$. Beyond the energetics, criteria of 
similar lattice parameters ${ }^{[96]}$ and chemical/structural similarity have been used to discovery of homostructural epitaxial polymorph stabilization ${ }^{[97]}$ and applied to match substrates and 2D materials ${ }^{[98]}$. Even further, by matching surface areas and comparing the similarities in the lattice vectors and the $x y$-strain, it is now possible to select pairs of substrates and films with the least incoherent interface ${ }^{[99]}$. This approach has been firstly used to investigate $\mathrm{VO}_{2}$ polymorphs on more than 60 different substrates ${ }^{[100]}$. Moreover, the same approach has later been used to identify substrates that can epitaxially grow the Pnna non-polar structure of $\mathrm{Ag}_{2} \mathrm{BiO}_{3}$, which shows a hourglass-Dirac-semimetal state ${ }^{[101]}$, to prepare the metastable leadfree piezoelectric $\mathrm{P} 4 \mathrm{~mm} \mathrm{SrHfO}_{3}{ }^{[102]}$ and permanent magnets ${ }^{[103]}$, to improve the optical properties of ferroelectric materials ${ }^{[104]}$.

These descriptors are based on structural bulk properties, and thus, no interfaces are calculated. Going beyond the bulk calculations come at the cost of a significant increase in complexity of the structures and of the required computational resources. Epitaxial surfaces are, thus, explicitly calculated only to answer to specific research questions, avoiding highthroughput approaches, as has been done for $\mathrm{TiO}_{2}$ polymorphs on $(\mathrm{Sr} / \mathrm{Ba}) \mathrm{TiO}_{3}{ }^{[105]}$ and for monolayer coatings on $\mathrm{TiO}_{2}$ polymorphs ${ }^{[106]}$. In addition to oxide interfaces, metal and nonmetal surfaces have also shown potential for stabilizing metastable structures, as shown for vanadium oxide on $\operatorname{Pd}(111)^{[107]}$ and for the interface between TiN and metal surfaces ${ }^{[108]}$ or titania ${ }^{[109]}$. Although not discussed here, this case opens up many more possibilities for paths towards metastability that could also generate exciting properties at the interface due to the different nature of the two materials involved.

Finally, we would like to emphasize that the descriptors discussed here are still based on bulk properties of the materials. An increased accuracy could be obtained by including information on the materials surfaces. This requires the development of large datasets for surfaces and a deeper integration between computational data and experimental results. 


\section{Energetic pathways towards interface metastability: experimental evidence}

Metastable materials remain largely heuristic and the scientific investigation especially cover examples of metastability that is directly involved in functional processes. These investigations include the cases where the coexistence of stable and metastable phases brings new synergies or chains of functional chemical/physical mechanisms. For metal oxides, the interface plays central role, as interface-metastability is the key in solid/environment processes in nanoparticles and thin films for heterogeneous catalysis, photocatalysis and photovoltaic, optical, electrical and electrochemical applications. The development of complex nanometric geometries, structures and heterojunctions has also brought new evidence of metastability at metal oxide solid/solid interfaces in nanocomposites, multilayers, core-shell nanomaterials and heterostructures ${ }^{[107,110-138]}$. The largest amount of experimental evidence of metastability is in polymorphic binary oxides such as $\mathrm{TiO}_{2}, \mathrm{ZnO}, \mathrm{CuO}, \mathrm{VO}_{x}, \mathrm{FeO}_{x}, \mathrm{SnO}$, and $\mathrm{ZrO}_{2}$, with an established technological impact. For metastable ternary oxides, $\mathrm{ABO}_{\mathrm{x}}$, metastability has an important impact on functionalities. ${ }^{[139-141]}$ However, analysis of the factors leading to metastability barely appears in the literature ${ }^{[115,129,142]}$. This deficiency is due to the complexity of tracking phase formations and/or segregation that, in multiphase systems, depend on dynamic and non-trivial boundary conditions ${ }^{[143-146]}$. For quaternary and more complex metal oxides, analysis of metastability becomes less practical and it is overlooked. On the other hand, solid/solid interfaces comprise defined chemical and structural boundaries that can facilitate the analysis of the interfacial energetic factors leading to controlled metastability conditions ${ }^{[138]}$. In this section, we resume the experimental work on such materials, highlighting some of the multi-fold effects controlling energetic transformations leading to metastability at the interfaces.

\subsection{Metastability at the free surface}


The most common case of metastability-interface interplay is at the solid/environment interface, where the crystalline structures of oxides terminate with broken chemical bonds and surface reconstruction. These structures include nanoparticles, nanocrystals, tailored nanostructures and thin films, where a large extension of the free surface, i.e., with a large aspect ratio between the surface and the volume core, can induce metastability in the materials. The energetic correlation between size and the polymorphism in a crystal is generally expressed as the sum, $G_{\text {tot }}$, of the bulk free energy content, $G_{\text {bulk }}$, and the surface energy, $G_{\text {surf }}{ }^{[147-149]}$. The size also decreases the path and hence shorten the kinetic scale of the phase transformation. As the kinetic scale decreases, temperature and pressure become the two main factors affecting the phase transformation, and for nanoscale sizes, $\mathrm{G}_{\mathrm{tot}} \approx \mathrm{G}_{\text {surf }}{ }^{[147,148]}$. The energy content at the surface collects several energetic contributions, such as the crystalline surface specific energies, surface stress and chemical energy of adsorbed species. For nanoparticles, manipulation via surface size, temperature and chemical treatments can thus allow directing polymorphic transitions, also in the metastable states ${ }^{[136,150,151]}$.

Metastability in polymorphic $\mathrm{TiO}_{2}$ films and nanocrystals is the most discussed case. The importance of titania mostly hinges on its photochemical and photovoltaic properties ${ }^{[152,153]}$, which arise from the coupling of the anatase (A) ground-state phase and the rutile (R) metastable form. The combination of these two phases, e.g., either in separate crystals or in the same crystalline domain ${ }^{[154-157]}$, works efficiently as a heterojunction between a $3 \mathrm{eV}$ band gap semiconductor (R) and a larger $3.2 \mathrm{eV}$ band gap (A), where electrons and holes can be trapped and excited by photonic and chemical mechanisms (Figure 3) ${ }^{[158]}$. In thermodynamic terms, the $\mathrm{R} / \mathrm{A}$ metastability in $\mathrm{TiO}_{2}$ is especially relevant as it occurs at low free energy changes below 30 meV/atom. Similar differences are also found in many other polymorphic metal oxides with technological relevance, including $\mathrm{ZnO}$ (wurtzite/zinc-blend), $\mathrm{V}_{2} \mathrm{O}_{5}$ (shcherbinaite/bronze/monoclinic), $\quad \mathrm{MoO}_{3} \quad$ (monoclinic/orthorhombic), $\quad \mathrm{ZrO}_{2}$ (tetragonal/monoclinic), $\mathrm{Al}_{2} \mathrm{O}_{3}$ ( $\alpha / \gamma$-phases), etc. (see Figure 2). Titania becomes thus 
representative of metal oxides with low difference between the energies of polymorphs and it appears especially sensitive to diffusion-less surface-related factors such as lattice strain, crystal defects and chemical sorption. As result, for high-density polymorphic metal oxides with lowenergy transformations, the size effect can be difficult to estimate and can lead to a large variety of metastable arrangements. Figure 4 schematically illustrates two possible cases of polymorphic transformations induced by size a reduction from the microscale to the nanoscale. Phase metastability occurs either abruptly in materials synthesized below a critical size (red crystals in Figure 4), as for $\mathrm{TiO}_{2}{ }^{[159,160]}$, or via a crystalline coexistence of the phases, e.g., as a core-surface arrangement (green crystal in Figure 4), as reported for $\mathrm{Bi}_{2} \mathrm{O}_{3}{ }^{[161]}$. A variety of other configurations are indeed possible and have been registered ${ }^{[162-166]}$. Due to the complexity and the relevance of the size effect for some oxides, predictions are often attempted over experimental evidence and both analytical and heuristic approaches for modelling a variety of experimental results to predict phase stability, e.g., accounting entropy, surface energy, internal pressure and particle shape ${ }^{[110,167]}$. However, equilibrium phase calculations generally do not include the important kinetic conditions found in high-density polymorphic nanomaterials, meaning that the topic is still open to interpretation and new implementations. Effect of size on low-energy polymorphs metal oxide is further discussed in 3.1.1.

For higher energy transformations, the energetic difference between phases can be difficult to achieve via surface energy factors. Another suitable example is the transition between monoclinic (M) and cubic (C) zirconia, with a difference in free energy above 70 meV/atom. In this case, the energetic contributions to metastability are higher and less probable than for monoclinic to tetragonal case with a difference in free energy of $c a .30 \mathrm{meV} / \mathrm{atom}$ (Figure 2). Experimental cases on high-energy polymorphs metal oxide are discussed in 3.1.2. An important feature of a high-energy phase transition $v s$ the low-energy one is that the kinetics of the transformation are slow and may require substantial readjustment of the crystalline structure from one phase to another, e.g., by elemental diffusion via thermal 
treatments and chemical processes (see sections 3.1.3 and 3.1.4). Diffusive paths and size are, however, interlinked factors, where structural defect and strain can also contribute (see sections 3.15 and 3.1.6).

\subsubsection{Size effect in low-energy transformations}

For nanometric titania, the literature on the size effect on phase stability is large. Tang et al. ${ }^{[168]}$ first reported the role of the surface in the coexistence and transitions of R/A phases for 30-40 nm nanocrystalline thin films. More recent developments have led to a variety of nanosized structures with high specific surface areas, such as mesoporous, core-shell, and composite nanocrystals, where stable/metastable phases coexist and activate functional heterojunctions, with or without the use of dopants or composite compositions ${ }^{[169-176]}$. Such chemical methods often involve the use of diverse parameters in the synthesis, such as various metal-organic precursors, ligands, variable low-temperature hydrolysis steps, diverse hightemperature oxygen bonding condensation and crystallization processes by calcination and hypercritical hydrothermal pressure/temperature conditions ${ }^{[177-184]}$. In other cases, physical synthesis is achieved through plasma-based processing with an unknown nucleation/growth mechanism ${ }^{[185-187]}$. All these methods surely involve a variety of mechanisms at the surface that, unlike the size effect, often cannot be tracked consistently for high-density polymorphs. Therefore, while the mere size effect, as in the case of nanoconfinement of the ideal $\mathrm{TiO}_{2}$ crystal, is generally considered the most important criterion for freezing metastability, in reality, chemical conditions during the synthesis can interfere with and have an important effect on the nucleation and coexistence of the phases ${ }^{[188,189]}$. Some recent studies indeed defined an order in their analysis, as the effect of the $\mathrm{pH}$ in water-based chemical methods has already been identified as a key factor in nanometric $\mathrm{TiO}_{2}$ polymorphism ${ }^{[190]}$.

In terms of surface-metastability interplay, it is necessary to define the extension of the metastable domain at the near-interface for a given crystalline material as the extension of the 
metastable phase from the surface to the bulk ${ }^{[191]}$. The critical size for the R/A transformation in $\mathrm{TiO}_{2}$ has been consistently found to be $c a \cdot 10-20 \mathrm{~nm}^{[184,192]}$. Large powders of hundreds of nanometers can contain $c a .60-80 \%$ anatase phase, and several lines of experimental evidence indicate an average extension of the metastable phase from the surface to the bulk of several tens of nanometers ${ }^{[193-195]}$. Structural characterization of nanocrystals below $10 \mathrm{~nm}$ generally shows metastability ${ }^{[192]}$, and interestingly, small anatase crystals become metastable when exposed to high thermal energy, where mass diffusion is expected to adjust the crystalline phases towards the stable rutile phase ${ }^{[196,197]}$. Other papers on nanometric titania report that the nucleation of the Gibbs phase is restored only above a critical size of $c a .20 \mathrm{~nm}$ via the coexistence between the anatase and rutile phases ${ }^{[149]}$. This evidence highlights the irreversibility of some metastable formations in nanoconfined systems and the critical role of the surface ${ }^{[198,199]}$. Other phases, such as brookite, and high-energy transformations can be observed at the nanoscale ${ }^{[110,200]}$ and some experiments have shown that dendrimer-based templates can even give access to the crystal nucleation chemistry of polymorphs via intermediate stages through high-energy metastable phases, e.g., via surface-adsorbed water and variation in the $\mathrm{pH}$ during growth ${ }^{[149,159]}$.

For other polymorphic materials with similar low energy transformation scales, where the energy difference between the ground state and the polymorph is below $10 \mathrm{meV} / \mathrm{atom}$, a reconstructive phase transition at the nanoscale also occurs. For example, the tetragonal-tomonoclinic phase transition in zirconia nanoparticles occurs below a threshold crystal size of ca. $20 \mathrm{~nm}{ }^{[148,201]}$, above which the monoclinic phase is stable. Tetragonal zirconia below a critical size of $10 \mathrm{~nm}$ is persistent and unlikely to transform into the monoclinic phase upon varying the thermodynamic conditions. The tetragonal phase thus becomes unstable with coarsening of only hundreds of nanometers by either promoting the coexistence of the two phases or undergoing a complete transformation into the monoclinic phase ${ }^{[182,202,203]}$. In zirconia, while the metastability at the surface is often associated with the lower surface energy 
of the tetragonal phase than the monoclinic phase, this coexistence is explained in terms of elastic energy and lattice strain that likely become dominant in larger crystals due to substantial difference in crystal volume between the two phases ${ }^{[182,204-207]}$. Similar effects of size on highdensity polymorphic binary metal oxides with low-energy transformations energies have been reported for $\mathrm{Al}_{2} \mathrm{O}_{3}{ }^{[208,209]}, \mathrm{ZnO}^{[210-212]}, \mathrm{VO}_{\mathrm{x}}{ }^{[20,107,137,213]}, \mathrm{Bi}_{2} \mathrm{O}_{3}{ }^{[161,214]}, \mathrm{MnO}_{\mathrm{x}}{ }^{[215]}$, etc. ${ }^{[216]}$.

\subsubsection{Size effect in high-energy transformations}

Although rarely reported, high-energy transformations leading to metastability in nanomaterials are possible, especially where high density polymorphism can also take place. However, comprehension of high-energy transformations in nanocrystals can be complex as transformation energy can result fragmented in diverse low-energy contributions. For example, while the coexistence of tetragonal and monoclinic phases is common in $\mathrm{ZrO}_{2}$, polymorphism involving cubic (undoped) zirconia does not appear to occur at the nanoscale, and phase changes in nano- $\mathrm{ZrO}_{2}$ occur by rapid changes in symmetry rather than long-range crystalline realignments. In a similar range of energies, there are other binary polymorphs such as $\mathrm{ZnO}-$ rock salt, cubic- $\mathrm{V}_{2} \mathrm{O}_{5}, \lambda-\mathrm{Al}_{2} \mathrm{O}_{3}$ and cubic $\delta-\mathrm{Bi}_{2} \mathrm{O}_{3}$. For bismuth oxide, the $\delta$-phase is rather frequent at both the nano- and macroscale ${ }^{[214]}$. This is more likely due to the concurrence of both the strong effect of the oxygen defects and fast mass diffusion that are accountable for $\mathrm{Bi}_{2} \mathrm{O}_{3}$-based compounds ${ }^{[217]}$. High-energy transformations can thus be explained in terms of elemental mobility and long-range crystalline realignments. Some significant examples are reported in 3.1.3.

Within the energetic barriers to polymorphism, the surface energy can also vary with the crystallography and morphology and increase the energy barrier to the transformation ${ }^{[182]}$. On $\mathrm{HfO}_{2}$ nanocrystals with well-defined morphologies in the 3-50 $\mathrm{nm}$ range, the free energy of the geometrically defined crystals is size-dependent, as the tetragonal-to-monoclinic phase transitions can vary with the shape of the crystal ${ }^{[218,219]}$. This and other evidence in $\mathrm{TiO}_{2}$ 
nanotubes $^{[220]}$ indicate that the dependence of the crystal structure on the surface energy for specific shapes and crystalline behaviours can be more significant in controlling phase stability at the nanoscale than the interface energy supplied by elastic contributions, e.g., by the film/substrate interface in thin films ${ }^{[218]}$. Moreover, a phase transition in the long-range order in a single crystal of a designed shape requires an overall higher energetic contribution, as phase transformation implies a change in the entire crystal or geometry. Size, crystalline behaviours and template geometries are often combined in polymorphic nanostructured materials. For $\mathrm{ZnO}$, energetic ordering in defined geometries can lead to a wide energy landscape promoting structures and surfaces with multiple forms of metastability ${ }^{[221]}$.

\subsubsection{Elemental diffusion at the surface}

As discussed in the case of high-energy transformations, the size becomes relevant in dynamical processes involving elemental diffusion. For metal oxides, oxygen is usually highly diffusive, and net mass diffusion is limited by the cations that are the slow species in ionic crystals ${ }^{[222]}$. Since diffusive paths are short at the nanoscale, mass diffusion for nanomaterials has a stronger impact than for bulky materials. Moreover, the surface possesses lower diffusion activation energy than the bulk does and it results faster at lower temperatures ${ }^{[223]}$. Figure 5 schematically shows the typical energetics of mass diffusion mechanisms for crystalline metal oxides, where elemental diffusion is facilitated at the surface and at the solid-solid interfaces and diffusive effects are more likely at lower temperatures than at higher temperatures ${ }^{[224]}$. This representation also implies that in nanomaterials at low temperatures, crystalline reorganization is more likely at the surface than in the crystalline core, i.e., at the lattice.

This effect is observed for cubic and tetragonal/monoclinic $\mathrm{ZrO}_{2}$, where the coexistence of energetically different phases can be detected in materials synthesized under diffusion-less conditions ${ }^{[225]}$. Conversely, some other oxides are prone to develop metastable phases, as their self-diffusion $\left(\mathrm{D}_{\text {self }}\right)$ mechanisms are fast. As comparison, zirconium self-diffusion is much 
slower $\left(<10^{-16} \mathrm{~cm}^{2} \mathrm{sec}^{-1}\right.$ at $\left.1000{ }^{\circ} \mathrm{C}\right)$ than that of $\mathrm{TiO}_{2}\left(\mathrm{ca} \cdot 10^{-12} \mathrm{~cm}^{2} \mathrm{sec}^{-1}\right.$ at $\left.1000{ }^{\circ} \mathrm{C}\right)$, and their activation energies for triggering cation mobility are rather different $\left(c a .3 \mathrm{eV} / \mathrm{Ti}\right.$ atom in $\mathrm{TiO}_{2}$ vs. ca. $6 \mathrm{eV} / \mathrm{Zr}$ atom for $\mathrm{ZrO}_{2}$ ). Therefore, while the $\mathrm{D}_{\text {self }}$ coefficient of the Ti cations in $\mathrm{TiO}_{2}$ and other polymorphic metal oxides such as $\mathrm{ZnO}, \mathrm{FeO}, \mathrm{NiO}$, and $\mathrm{CuO}$, is rather high $\left(\mathrm{D}_{\text {self }}=\right.$ $10^{-12} \mathrm{~cm}^{2} / \mathrm{sec}$ at $1000{ }^{\circ} \mathrm{C}$ ), other compounds, such as $\mathrm{Al}_{2} \mathrm{O}_{3}$ and $\mathrm{ZrO}_{2}$, have much lower selfdiffusion $\left(<10^{-14} \mathrm{~cm}^{2} / \mathrm{sec}\right.$ at $\left.1000{ }^{\circ} \mathrm{C}\right)$ and phase transitions unlikely occur at low temperatures. In nanometric $\mathrm{HfO}_{2}$, another fluorite-structured oxide with even slower cation self-diffusion (i.e., $<10^{-17} \mathrm{~cm}^{2} \mathrm{sec}^{-1}$ at $1000{ }^{\circ} \mathrm{C}$ ), shaped as supported thin films and free-standing nanometric thin-wall nanotubes, the size dependence of the tetragonal-to-monoclinic phase transitions is also observed for a critical size of $c a .2 \mathrm{~nm}$, although these transitions do not include cubic symmetry ${ }^{[218,226]}$.

If structural features and defects at the surface can affect phase transitions, thermally activated fast cationic mobility can be disruptive, as a change of symmetry occurs with extensive reconstruction of the lattice ${ }^{[227]}$. The scenario becomes even more complex in the case of polymorphic phases coexisting in metal oxides with fast mass diffusion and high-density polymorphism, i.e., with several different symmetries with similar and incremental energetic contents including high-energy transformations. This is the case of bismuth oxide with very rapid self-diffusion $\left(D_{\text {self }}>410^{-10} \mathrm{~cm}^{2} \sec ^{-1} \text { at } 780{ }^{\circ} \mathrm{C}\right)^{[217]}$ and high-density polymorphism $(\alpha-$, $\beta$-, $\gamma$ - and $\delta$-phases) in a relatively limited temperature range (melting point at $817^{\circ} \mathrm{C}$ ) ${ }^{[228]}$. For bismuth oxide, the transformations include several phase transformations at low energy below $50 \mathrm{meV} /$ atom as well as a high-energy transformation from $\alpha-\mathrm{Bi}_{2} \mathrm{O}_{3}$ to $\delta-\mathrm{Bi}_{2} \mathrm{O}_{3}$ above 70 meV/atom (see Figure 2). Bismuth oxide nanoparticles can thus either present mono-dispersed phases in a competition between stability and metastability or even a conundrum of coexistent metastable phases ${ }^{[161][229]}$. Investigations on the size-dependent thermodynamic properties of 6-50 nm $\mathrm{Bi}_{2} \mathrm{O}_{3}$ nanoparticles have shown that monodisperse, monocrystalline $\beta-\mathrm{Bi}_{2} \mathrm{O}_{3}$ nanoparticles are dominant at the nanoscale, while multiphase $\alpha$ - and $\delta-\mathrm{Bi}_{2} \mathrm{O}_{3}$ systems are 
generally observed above a critical size of 50-100 nm. The coexistence of $\alpha$ - and $\delta$-phases at the core and surface, respectively, is generally associated with the higher stability of the $\delta$-phase at higher temperatures ${ }^{[228]}$. However, polymorphism in $\mathrm{BiO}_{\mathrm{x}}$ presents several unexpected effects, as the material generally has abundant oxygen defects, i.e., oxygen vacancies, while bismuth is rather diffusive and easily reduced to the (volatile) metallic form ${ }^{[230,231][232]}$.

For $\mathrm{Bi}$-derived compounds such as the multiferroic $\mathrm{BiFeO}_{3}$ system, inhomogeneity due to uneven mass diffusion effects can also lead to multiple phase transitions, both in the bulk and at the nanoscale. The complexity of the polymorphism arises from thermal treatments as well as the susceptibility of the lattice structure to developing oxygen vacancies. In $\mathrm{BiFeO}_{3}$ nanoparticles, fast cation migration leads to lattice strain-induced oxygen vacancy formation with high energetic contents ${ }^{[233]}$.

\subsubsection{Chemical reaction at the surface}

Similar to $\mathrm{Bi}_{2} \mathrm{O}_{3}, \mathrm{Al}_{2} \mathrm{O}_{3}$ also exists in a wide range of polymorphs ${ }^{[234]}$. However, the density of polymorphisms in $\mathrm{Al}_{2} \mathrm{O}_{3}$ nanoparticles is rather low, although still size-dependent ${ }^{[235,236]}$. Alumina is characterized by the rather slow cation mobility of $\mathrm{Al}\left(\mathrm{D}_{\text {self }} \sim 10^{-16} \mathrm{~cm}^{2} \mathrm{sec}^{-}\right.$

${ }^{1}$ at $1000{ }^{\circ} \mathrm{C}$ ) that does not allow extensive crystalline realignment at low temperatures. However, phase transformations in alumina occur and are associated most often with a direct $\mathrm{Al}_{2} \mathrm{O}_{3}$ reaction with $\mathrm{H}_{2} \mathrm{O}$ that can form intermediate phases as reaction products that are energetically closer to the high energy phases ${ }^{[235]}$. In such terms, foreign chemical species become an effective way to enhance cation mobility and favour phase transformations. Therefore, the stable $\alpha-\mathrm{Al}_{2} \mathrm{O}_{3}$ form that comes directly from the oxyhydroxide is $\alpha-\mathrm{AlOOH}$ (diaspore), while $\gamma$-AlOOH (boehmite) is a metastable phase that induces the formation of different phases via dehydration and, e.g., $\alpha-\mathrm{Al}_{2} \mathrm{O}_{3}$ formation under controlled hydrothermal conditions ${ }^{[234]} \cdot \alpha-\mathrm{Al}_{2} \mathrm{O}_{3}$ nanoparticles below $100 \mathrm{~nm}$ are likely to form at low pressure, and metastable $\gamma-\mathrm{Al}_{2} \mathrm{O}_{3}$ nanocrystals are generated at a critical size of $c a .10 \mathrm{~nm}{ }^{[236]}$. The 
coexistence of stable/metastable and multiple phases in nanocrystalline alumina has not been reported so far, as different synthetic procedures seem to promote either one phase or another but not coexistence. For the synthesis of metastable $\gamma-\mathrm{Al}_{2} \mathrm{O}_{3}$ nanocrystals, one of the more common routes is to heat boehmite at temperatures above $450{ }^{\circ} \mathrm{C}^{[235,237,238]}$. Since mass diffusion is slow, the metastable $\gamma-\mathrm{Al}_{2} \mathrm{O}_{3}$ formed sticks to the synthetic precursor, and crystalline realignments do not occur. As a consequence, the size-dependent effects for alumina are not as pronounced as those for other oxides, and the formation of metastable 3-5 nm particles takes place via the low-temperature metal-organic chemistry of aluminium complexes with oxidizing agents. Further thermal treatment does not lead to phase transformation during calcination ${ }^{[235]}$. From the chemical point of view, the oxygen defect/metastability interplay at a metal oxide interface is the most discussed case of reactivity at the surface leading to metastability. This is the case of direct interaction of water molecules with oxygen vacancies in metastable tetragonal $\mathrm{ZrO}_{2}$, yielding monoclinic $\mathrm{ZrO}_{2}$ in an example of corrosion in metastable zirconia ${ }^{[239]}$. Similarly, the equilibrium boundary between anatase and rutile nanocrystals is surface charge chemistry dependent, which relates to both their formation and post-synthesis environments ${ }^{[188]}$. The combination of size, shape and thermal conditions can shift the equilibrium with water, leading to $\mathrm{OH}_{2}$ - and $\mathrm{OH}$-terminated surfaces. The nanoscale effect and surface chemistry interplay in $\mathrm{TiO}_{2}$ nanocrystals switch stability from one phase to another.

For iron oxide $\left(\mathrm{Fe}_{2} \mathrm{O}_{3}\right)$, surface chemistry is critical to phase stability ${ }^{[191]}$. Iron oxide has high-density polymorphisms within a wide range of energies. However, the material can easily be converted into multiple metastable states through the reaction of the compound when it is in contact with external chemical species. Readapted from Navrotsky et al. ${ }^{[151]}$, Figure 6 shows that iron oxide exists in a rich variety of hydrates nucleated by a direct reaction with its surface ${ }^{[150]}$. Remarkably, the energetic landscape for the anhydrous form and the surface significantly contributes to the phase transformations. The competition between surface 
enthalpy and reaction energetics can thus lead to multiple arrangements of thermodynamically stabilized polymorphs at the nanoscale (dashed area in Figure 6). The size-driven thermodynamic differences between iron oxide and hydroxide phases are, in fact, so close that they are fairly difficult to predict, as external factors can influence the phase stability at the nanoscale ${ }^{[151]}$.

\subsubsection{Surface strain and metastability}

Among the extrinsic energetic factors influencing metastability in surfaces, lattice strain plays an important role. In high-density polymorphisms, where stable and metastable phases have comparable energies, slight differences in the lattices can easily induce crystalline realignments and metastable phase formation. Lattice strain is generally imposed over surfaces and interfaces by external factors, such as environmental pressure, and by applied mechanical stress, e.g., by other solids and coexisting phases. ${ }^{[13,240,241]}$ Therefore, while the strain from environmental pressure can change under different operating conditions, other solids and phases can exert stress constantly, e.g., via either direct contact or structural continuity with lattice misfit of the lattices. High strain values can also lead to plastic distortion and nucleation of defects in the lattice ${ }^{[242,243]}$. Therefore, for careful analysis of the strain effect on metastability that does not encompass the overlap of other effects such as defects, we need to rely on well-controlled crystalline phases.

For functional metal oxides, the most rigorous cases generally refer to semi-coherent and coherent epitaxial films, such as those in thin films deposited on single crystal-like substrates ${ }^{[11,244,245]}$. However, while for semi-coherent films uniform lattice strain cannot determined as grain boundaries and dislocation are formed by the large lattice mismatch with the substrate, coherent epitaxial film represent an ideal case for the analysis of the lattice strain generated at the interface. Figure 7 schematically summarizes some possible cases, highlighting three different configurations reported in the literature ${ }^{[198,246-248]}$. On the left, 
Figure 7 displaces a fully strained lattice, highly coherent with a low strain level inducing phase change and metastability in the full lattice. At the centre, it shows higher strain level inducing phase transformation at the film/substrate interface and relaxation at the surface, resulting in the coexistence of different phases. At the right, it shows semi-coherent epitaxial thin films with high structural strain leading to plastic deformation (grain boundary in Figure 7), defects and thus relaxation of the lattice in the residual coherent regions. The last of the three cases is nonhomogeneous and it falls in either the domain of strained or relaxed materials, depending on the actual microstructure and the amount disordered/amorphous lattice at the interface. The high strain case, including coexistence of polymorphs, directly affect the free surface and it is relevant for the formation of metastable phases. Strain effects can also include more complex structures and configurations such as core-shell, mesoporous and nanocomposite structures, where the use of crystalline molecular templates provides access to crystal nucleation chemistry and nanoparticles with strained nucleation sites and interfaces ${ }^{[149]}$.

For stable/metastable phase coexistence (Figure 7 centre), the mismatch between the metastable phase at the surface and the stable core of the film introduces mechanical energetic contributions. For example, in titania, the difference lattices between anatase and rutile crystals induces a large structural mismatch at their interface ${ }^{[249]}$. However, such a difference at the two phases lattices is minimized by the reciprocal crystallographic orientations at the interface ${ }^{[246]}$. For epitaxial thin films, the extension of the surface can make these contributions of elastic energy relevant to the existence of metastable phases. This is registered for titania thin films deposited over a wide range of differently oriented single-crystal substrates ${ }^{[247]}$. The anatase/rutile transition becomes competitive on substrates that can either impose compressive or tensile strain, i.e., -2 and $6 \%$, by the lattice mismatch between $\mathrm{TiO}_{2}$ and the substrate. Experimental observations also show that the elastic strain energy of up to $5 \%$ and higher dominates and leads to anatase stabilization, even with a change in orientation. For high lattice strain, the epitaxial films nucleate disordered regions (as shown in Figure 7 (right)) and 
degenerate into nanocrystals, where other polymorphs can be further favoured. For $\mathrm{TiO}_{2}$ prepared by pulsed laser deposition that grows as (001)-oriented anatase on (001) $\mathrm{LaAlO}_{3}$ (LAO) and (001) $\mathrm{SrTiO}_{3}$ (STO) substrates, where the film quality improves as the lattice mismatch is reduced. The film thickness also affects the phases: as the thickness increases, the lattice strain is relieved. Other cases show that the epitaxial growth of $\mathrm{TiO}_{2}$ on both $\mathrm{SrTiO}_{3}$ (011) and (111) substrates can lead to changes in orientations in anatase films or even formation of metastable rutile. This effect results from the large mismatch between anatase and the substrate: since rutile fits to the substrate better than does anatase, the metastability here is favoured with respect to polycrystalline disorder in anatase growth ${ }^{[246,247]}$. Other examples of epitaxial (001)- and (012)-oriented $\mathrm{TiO}_{2}$ on variously oriented Y-stabilized zirconia (YSZ), STO and LAO substrates show a full tunability of phase nucleation via a combination of lattice strain and deposition conditions. As shown in Figure 7 (centre), such strain can induce polymorphisms with mixed anatase and brookite and pure phase formations ${ }^{[246]}$.

\subsubsection{Defects and metastability}

One of the most important features of metal oxides is their capability to incorporate a variety of diverse structural defects in their lattice. Crystalline defects at the surface are known to be reactive and directly involved in catalytic, optical, electronic and photo-effects ${ }^{[250]}$. Although defects are crucial in metal oxides, a direct correlation between defects and metastability has not yet been clearly established. The presence of punctual defects is an energetic factor that particularly influences the energy of the compound, as they induce lattice distortion and electrostatic localized fields in the lattice. Due to the close interplay between defects and strain, a clear separation between these two factors is not always possible.

Although controlled by either kinetic or thermodynamic factors, structural defects in metal oxides become dominant when chemical factors, such as impurities and doping, are introduced into the crystal. These chemicals act as dopants that are able to balance the 
electrostatic interactions in the ionic crystal and the structural defects ${ }^{[251]}$. Kinetic defects that are generated under non-equilibrium conditions are often associated with fast thermal treatments and can be discussed as a result of nucleation and non-equilibrium growth, e.g., the process used to synthesize the material (see section 3.1.3). At equilibrium, high-energy defects tend to concentrate and associate where the free energy of the crystal is higher, at grain boundaries, at solid-solid interfaces, at the free surfaces and around segregations, impurities and disordered regions. For example, oxygen defects, i.e., oxygen vacancies $\left(\mathrm{V}_{\mathrm{o}}\right)$, before being incorporated into the lattice are nucleated at the solid/gas interface as the result of oxygen gas desorption. Similar considerations can be extended to other kinds of defects in metal oxides, such as interstitial ions and impurities in contact with reactive species, e.g., Li, $\mathrm{H}$, and $\mathrm{Na}$ ions. The dynamics of such surface reactions can thus make the difference between kinetically trapped and equilibrium defects, with rather diverse concentration gradients between the core and the surface (see Figure 8 for a schematic representation) ${ }^{[252-256]}$.

As in chemically reduced rutile $\mathrm{TiO}_{2}$, oxygen sub-stoichiometry $\left(\mathrm{TiO}_{2-\mathrm{x}}\right)$ can lead to progressive phase transformations at the surface and $\mathrm{V}_{\mathrm{o}}$ formation that is energetically more favourable in anatase than rutile ${ }^{[257,258]}$. In contrast, a long reduction of the metastable $\mathrm{TiO}_{2}$ rutile can also destabilize the anatase surface for specific crystallographic orientations and induce the formation of interstitial Ti more easily in rutile than anatase ${ }^{[194]}$.

Other cases of defect nucleation at the metal oxide $(\mathrm{MeO})$ surface are more complex, as in the case of $\mathrm{ZnO}_{1-\mathrm{x}}$, where there is still debate on the different intrinsic defects such as oxygen vacancies, oxygen interstitials, zinc interstitials, and zinc vacancies $\left(\mathrm{V}_{\mathrm{Zn}}\right)$ and how these defects can influence metastability ${ }^{[259]}$.

For zirconia, several lines of evidence clearly indicate that in $\mathrm{ZrO}_{2-\mathrm{x}}$, anionic vacancies and electronic defects are favoured in the metastable tetragonal phase, and the monoclinic phase generally nucleates where oxygen defects are compensated by reoxidation ${ }^{[225,260,261]}$. Further proof of such an effect has been recently reported for off-stoichiometric $\mathrm{ZrO}_{2-\mathrm{x}}$ nanofibres 
synthesized under a controlled reducing atmosphere. These nanofibres turn into highly conductive black zirconia, along with crystallization of the tetragonal phase even after long post-treatments at high temperatures $\left(>700{ }^{\circ} \mathrm{C}\right)$ in air ${ }^{[262]}$.

In iron oxide, phase stabilization mechanisms occur via cation rearrangement in the lattice as a consequence of redox conditions at the surface ${ }^{[191]}$ where oxygen vacancies are formed. Remarkably, at equilibrium, an oxygen vacancy concentration gradient between the surface and the bulk occurs as an effect of the electronic structure of the reactive broken bonds, primarily via the cations at the surface. Moreover, the various polymorphs in iron oxide present two cation configurations, i.e., octahedral and tetrahedral interstitial sites, that can incorporate slightly different amounts of cationic defects ${ }^{[191,263]}$. Even in this case, evidence shows that cation diffusion plays a crucial role in metastable phase formation via structural readjustment at the surface.

Other oxides with low-density polymorphism, such as $\mathrm{CoO}, \mathrm{MnO}$, and $\mathrm{NiO}$ with phase transitions from rock-salt to spinel and corundum, exhibit similar cation redistributions at the surface in reducing and oxidizing environments, so such reconstructions can also occur for those materials ${ }^{[264]}$.

In addition to environmental and kinetic factors, the most direct way to produce stable defects in metal oxides is by substitutional doping. Introducing extrinsic defects is a common way of tuning properties, where the defect concentration depends on the dopant concentration ${ }^{[256]}$. Substitutional cations with different sizes and valences have the dual effect of inducing local elastic distortion of the lattice and producing electronic defects in the lattice, respectively. Because of this dual effect, cubic $\mathrm{ZrO}_{2}$ is stable at low temperatures, suppressing the formation of the monoclinic and tetragonal phases in highly doped zirconia with several aliovalent elements including Y, Sc, Ca, etc. ${ }^{[256]}$. Similarly, in $\mathrm{Bi}_{2} \mathrm{O}_{3}$, the use of an acceptor dopant can stabilize the $\delta$-phase at room temperature relative to the Gibbs $\alpha$-phase ${ }^{[265]}$. For the interplay between the extrinsic defects and free surface, there is no direct evidence that dopants 


\section{WILEY-VCH}

can alter the energy of the surface towards metastability. Conversely, as the dopants act as phase stabilizers, polymorphism is generally suppressed. Aliovalent dopants are generally different in size from the hosting cation, and their diffusion can lead to vacancy association and other subtle segregation effects, as in the case of the solute drag diffusion effect ${ }^{[266]}$. This is seen in highly doped fluorite and in alkaline earth-doped perovskite structures. Some examples are $(\mathrm{La}, \mathrm{Sr}) \mathrm{MnO}_{3},(\mathrm{La}, \mathrm{Sr}) \mathrm{FeO}_{3}$ and $(\mathrm{La}, \mathrm{Sr}) \mathrm{CoO}_{3}$, where the large electro-steric mismatch between the hosting $\mathrm{La}$ and $\mathrm{Sr}$ dopant generally leads to a destabilization of the perovskite phase along with cation demixing at the surface (see also Figure 8, right hand side) ${ }^{[267]}$. In this kind of transformation, defects and chemical environments play an important role, and as further discussed in section 3.2, nanoconfinement becomes relevant ${ }^{[123,135,268-270]}$.

For doped and ternary metal oxides, the free surface is generally the location of chemical reactivity, where dopants and their related electronic defects find energetic convenience in segregating at the surface and near-interface regions. This behaviour has a direct effect of tuning the energetic content at the surface and directing polymorphic transformations towards different energetic pathways. Clear evidence in $\mathrm{TiO}_{2}$ shows that while metastable anatase predominated at the surface in undoped $\mathrm{TiO}_{2}$ nanopowders, $\mathrm{Fe}^{3+}$ doping can induce the formation of rutile at the surface ${ }^{[271-273]}$. This effect is generally attributed to the lattice distortion and elastic energy content, as $\mathrm{Fe}^{3+}$ has an active size of $0.55 \AA$, which is lower than that of $\mathrm{Ti}^{4+}(0.60 \AA)$, thereby shrinking the lattice and favouring the rutile phase. However, as acceptor dopant, $\mathrm{Fe}^{3+}$ can also form extrinsic oxygen vacancies that, in reduced titania, tend to stabilize rutile. The amounts of dopant and segregation effects play a central role in such transformations.

For polymorphism, dopants and extrinsic defects bring extreme consequences in the case of high-entropy metal oxides ${ }^{[274,275]}$. These compounds are attracting growing scientific interest driven by their enhanced and mostly unknown functional properties. Pure fluoritestructured entropy-stabilized oxides have been synthetized with compositions containing Ce, $\mathrm{Zr}$, Hf, Y, Yb, Gd and $\mathrm{Ca}$ oxides ${ }^{[275]}$. Considering their fluorite structure and the presence of 
oxygen vacancies (for balancing the charge of trivalent ions), these materials should be highly unstable. However, since high-entropy oxides are composed of at least 5 different cations, the different atomic radii of the cations induce additional distortion of the lattice, which is expected to modify the cation arrangement in the vicinity of oxygen vacancies, with high complexity at the interfaces. The cationic disorder in high-entropy oxides has the additional effect of increasing the entropic term in the Gibbs free energy, with the consequence of lowering their Gibbs' free energy and stabilizing the material.

\subsection{Metastability at solid-solid interfaces}

In contrast to the free surface that readily relaxes and reacts, solid-solid interfaces in defective metal oxides have a high degree of tunability, as they are less dependent on the ambient conditions. This is especially true for epitaxial structures, where the lattices share the different components and the interface is the boundary between coherent structures. In such a configuration, structural features such as strain, defects and disorder gather at the near-interface region in a relatively tuneable fashion. In this section, we explore the relation between these features and metastability and introduce how this can be used to design material properties.

\subsubsection{Lattice strain, defects and metastability}

Several studies have shown that strain and defect engineering at the solid-solid interface can tailor physical properties in functional materials ${ }^{[135]}$. For metal oxide materials that share a coherent interface or are stacked in an epitaxial heterostructure, this concept has been applied in a variety of compositions, generating new phenomena and devices ${ }^{[10]}$. Due to advances in the thin-film deposition of epitaxial films, strain engineering has mainly been reported in the planar structures of thin films and multilayers. Other studies also report strain in more complex geometries such as nanowires, ribbons and core-shell structures ${ }^{[276]}$. In all these cases, the lattice strain introduces elastic energy that is stored in the near-interface region of a few 
nanometers. Outside the near-interface region, structures generally relax and recover the pristine lattice dimensions. Although the strain is expected to induce relaxation a few atomic layers away from the interface, several examples reported in the literature suggest that epitaxial films can maintain a relatively long-range strain in the lattice and that metastable states form at the surface ${ }^{[247]}$. In the planar thin-film case, the degree of strain is gradually reduced with the thickness and width of the films. The mismatch between the substrate and film regulates the strain between the lattices at the interface that remains coherent for low values of strain, generally below $4-5 \%^{[11]}$. For larger mismatches, a large disorder is introduced in the lattice at the near-interface regions (see Figure 7), e.g., by dislocation and grain boundaries. For epitaxially grown thin films, disorder typically consists of vertically aligned grain boundaries, dislocations and defect associations generated by plastic deformation of the lattice. When disorder is introduced into the structures, the lattice becomes semi-coherent, and ordered regions are generally relaxed ${ }^{[11]}$. On the other hand, at strained coherent interfaces, punctual defects can be introduced at the near-interface regions, making an important contribution to interface properties. However, to date, only a few studies have reported a direct relation between strain and metastability in metal oxides ${ }^{[127,225,277,278]}$. In epitaxial vanadium dioxide grown on $\mathrm{Al}_{2} \mathrm{O}_{3}$, strain induces polymorphism complex nanophase separation of $\mathrm{VO}_{2}$ for a nearinterface distance of typical below $40 \mathrm{~nm}{ }^{[279]}$. As discussed in section 3.1.5, studies on $\mathrm{TiO}_{2}$ thin films, as well as on iron oxide and complex oxides, have highlighted the tunability of lattice strain in $\mathrm{TiO}_{2}$ over a wide range of differently oriented perovskite substrates.

For polymorphic materials with high-energy transformations, the high elastic energy content is often associated with disorder, for example, in a polycrystalline metal oxide with a large number of grain boundaries, e.g., in zirconia ceramics, $\mathrm{BaTiO}_{3}$, and $\mathrm{BiFeO}_{3}$, where elastic energy between grains can induce the coexistence of stable and metastable phases with rather different formation energies ${ }^{[280]}$. For $\mathrm{ZrO}_{2}$, the common low-energy polymorphic transformation from the tetragonal to the stable monoclinic phase at room temperature is 
sometimes accompanied by the presence of amorphous and cubic phases with large energy variations ${ }^{[205,281]}$. In this scenario, the continuum elastic model has importance in the definition of the different energies at the interface and can practically contribute to the energy competition to promote one phase rather than another.

In a recent paper on dopant-free $\mathrm{ZrO}_{2}$ non-coherent thin films with highly defective microstructures, we showed that a combination of oxygen defects and strain can lead to unexpected polymorphisms ${ }^{[225]}$. Oxygen vacancy-stabilized zirconia (OVSZ) is obtained in thin films chemically tuned during deposition at low oxygen partial pressure that can lead to the formation of metastable cubic zirconia with a remarkable landscape of metastability both at different temperature and for various oxygen partial pressures. Interestingly, the cubic stabilization is dependent on the thickness of the films, where thin films below $50 \mathrm{~nm}$ are fully cubic with high electrical properties and thicker films can nucleate a complex arrangement of monoclinic and tetragonal phases. This critical thickness in OVSZ is related to strain imposed by the substrate on the film, which, despite being polycrystalline, presents a homogeneous and dense microstructure at the near-substrate interface (Figure 9).

Bismuth oxide probably has the most interesting effects related to phase-vacancy interactions, as the disorder/disorder transitions that are associated with different oxygen vacancy configurations control its high density of polymorphs with both high- and low-energy transformations (see Figure 2). Several lines of experimental evidence show that the interface can freeze metastable phases ${ }^{[127,277,278]}$. Interfaces that effectively freeze metastability both through strain and the formation of highly defective phases are also reported. The highly defective $\delta$-phase, with disordered defects, seems to be favoured under both high- and lowstrain conditions. The defective $\delta$-phase has the highest relevance because it possesses the highest oxygen ionic conductivity reported thus far. However, the oxygen defect concentration also plays a key role in the polymorphic transformation, and while the cubic defective $\delta$-phase 
is expected in acceptor-doped materials, other phases occur in coherent crystals ${ }^{[265]}$. Even for epitaxial thin films, the stabilizing effect of the dopant seems to be irrelevant, where the material becomes coherent under chemical or electrochemical conditions that nominally should lead to a measurable lattice strain ${ }^{[282]}$. Such effects appear rather unpredictable and are often accompanied by large diffusive phenomena, including elemental microstructural rearrangement and interdiffusion with other solids ${ }^{[283,284]}$. Moreover, bismuth diffusion is strictly dependent on the oxygen partial pressure $\left(\mathrm{pO}_{2}\right)$ in the environment and is prone to chemical reduction at low $\mathrm{pO}_{2}$ that, via oxygen gas formation, can lead to bismuth in its metallic form. Metallic bismuth has a low melting point and is highly volatile and reactive towards moisture ${ }^{[285]}$. Despite such limitations, bismuth oxides represent an interesting example of a material that is nanoengineered through solid-solid interfaces and a material where the metastability of the desired $\delta$-phase can be preserved under non-equilibrium thermodynamic conditions. This case is further discussed in following section 3.2.3, where materials structured in the nanoscale with other solids, between interfaces, show resistance against chemical degradation and phase transformations.

\subsubsection{Effects of nanoconfinement in composites and heterostructures}

The concept of confining a defective metal oxide between interfaces in a coherent fashion has long garnered widespread interest from the material science community ${ }^{[286]}$. The subject is rather broad and includes the possibility to combine the properties of different materials, to enhance the effect of the interface by multiplication of the interface in $2 \mathrm{D}$ multilayers ${ }^{[287]}$ or to expose unstable phases to reactive environments ${ }^{[288,289]}$. Concerning the interplay between metastability and interfaces, the basic mechanisms of phase stability can be analysed in coherent structures simply by extending the near interface region throughout the whole materials. In such a configuration, the broken symmetry is at the interface and propagates from one side to another in an extended range such that the lattice cannot relax. The repeating 
interfaces thus become a structural tool to keep strain and defects in the long range, incorporating sufficient energy into the material to obtain metastable states. Figure 10 schematically represents this and other possible configurations and it summarizes some experimental evidence for heterostructures. This includes the effect of lattice strain in nanoconfined layers (top-right side), electrostatic interaction between materials at the interface (centre-right side), and chemical barrier effects at the solid-solid interface (bottom-right side).

For the strain effect (top-right side in Figure 10), the use of multilayers with reduced thickness can avoid relaxation at the near interface, thus inducing the stabilization of fully strained phases at the repetition, as discussed in section 3.1.5.

For the electrostatic stabilization (centre-right side in Figure 10), one of the most frequent effects at solid-solid interfaces for metal oxides is the formation of space charge regions with charge depletion regions next to the interface, i.e., by the gathering of electrostatically balanced defects at the interface ${ }^{[11]}$. On the other hand, the presence of defects and different cations at the interface can both electrostatically and sterically affect the structured phases, thus inducing at the interface a doping-like effect that, similar to the effect observed from a dissolved punctual dopant (i.e., solute and/or substitutional dopants), can stabilize metastable phases along the $2 \mathrm{D}$ interfaces. This is also what occurs in depleted regions or blocking barriers and junctions, where the abrupt changes in chemical species concentration produce local electrostatic fields and lattice polarization ${ }^{[11]}$. Through nanoconfinement, the whole structure can be affected by forming and repeating in the multilayer a metastable phase with a segment charge distribution that, as in the case of nanoionics ${ }^{[289,290]}$, can lead to enhanced electrical properties. In terms of just metastability, the only example discussed in the literature so far is $\mathrm{Bi}_{2} \mathrm{O}_{3}$ nanoconfined in thin film multilayers with other fluorite materials ${ }^{[277,278]}$ This phenomenon happens especially in the case of undoped $\mathrm{Bi}_{2} \mathrm{O}_{3}$ within YSZ heterostructures ${ }^{[278]}$. These results show a wide range of existence for the $\delta$-phase at high temperatures $\left(750{ }^{\circ} \mathrm{C}\right)$ and room temperature, with no changes in symmetry towards other polymorphs. Heterostructures 
within thin bismuth oxide layers especially show signs of electrostatic stabilization. Structural data from in situ X-ray diffraction characterization indicate the persistence of the cubic symmetry of the $\delta$-phase versus the more stable Gibbs phase of $\alpha-\mathrm{Bi}_{2} \mathrm{O}_{3}$ despite the large lattice mismatch of (5.4 $\AA$ for the $\delta$-phase vs. ca. $7.5 \AA$ for the $\alpha$-phase) ${ }^{[278]}$. This result can be explained either by strain effects on the confined $10-20 \mathrm{~nm} \mathrm{Bi}_{2} \mathrm{O}_{3}$ layers or, for the thicker layer, by interfacial polarization of the YSZ component over the pure bismuth oxides that can thus result in stabilization in the $\delta$-phase by the periodic repetition of the aliovalent elements. Remarkably, the electrical properties of such systems also resemble those of the $\delta$-phase with an extraordinary synergy between the ionic properties of YSZ and the bismuth oxide component

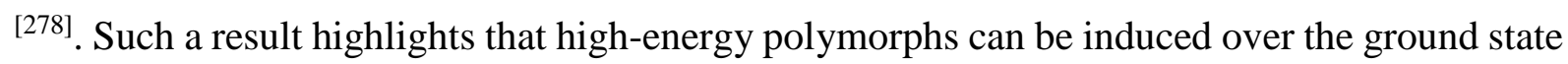
via a solid-solid interface. Moreover, interface repetition in a multilayer may result in a practical way to overcome lattice relaxation at the far-interface regions, allowing space charge regions with desired spatial distribution and composition in the long range to be built.

For the chemical barrier effect (bottom-right side in Figure 10), the characterization of the lattice parameters during the thermal evolution of the multilayer shows a rather persistent arrangement of the $\mathrm{Bi}_{2} \mathrm{O}_{3}$ structure around the $\delta$-phase lattice as a consequence of overall matching of the bismuth oxide structure with the YSZ lattice. Interestingly, this symmetry is also preserved at low oxygen partial pressure and at high temperatures, where high diffusivity of bismuth is expected ${ }^{[278]}$. These features are also reported in the case of erbium-stabilized bismuth oxide (ESB) nanoconfined in multilayered thin films with cerium oxides ${ }^{[277]}$. For ESB, the chemical stability of the $\delta$-phase extends to reducing conditions in the presence of $\mathrm{H}_{2} / \mathrm{H}_{2} \mathrm{O}$ at high temperatures, i.e., above $650{ }^{\circ} \mathrm{C}{ }^{[277]}$. This result is extraordinary for $\mathrm{Bi}_{2} \mathrm{O}_{3}$, not only because fast reduction to the metallic form is expected in hydrogen but also because unusual electrical properties along with high conductivity and mixed electronic and ionic properties are reported for the nanostructure ${ }^{[277]}$. The role of the interface in the diffusive mechanisms in ESB 
and Gd-doped cerium oxide (CGO) heterostructures (ESB/CGO) is also confirmed by the fact that the physical properties are modulated by both the reciprocal thickness and number of interfaces. Further complexity is added to this case by the fact that cerium oxide undergoes chemical expansion at low oxygen partial pressure and high temperatures ${ }^{[277]}$. Therefore, in the multilayer of $\mathrm{CGO}$, chemical strain of up to $1.5 \%$ is directly imposed on the ESB component; as the $\delta$-phase shows a rather wide potential to endure strain and incorporate defects, a single phase maintained when nanoconfined. On the other hand, thick ESB films in the CGO multilayer undergo chemical reduction above $c a .50 \mathrm{~nm}$, showing that mass diffusion is suppressed only in the nanoconfined case. Therefore, as the thickness increases, diffusive effects occur, and both microstructure and phase realignments can occur.

The presence of solid-solid interfaces is known to affect cation diffusion via the socalled chemical barrier effects, where the encapsulated materials can effectively reduce the mass migration in diffusive oxides through a physical effect on the most diffusive species and chemical confinement induced by insolubility ${ }^{[291,292]}$. This topic is indeed widely reported in the literature for metal oxides, especially in cases where direct chemical intermixing between functional layers and components has to be avoided ${ }^{[293]}$. With regard to metastability, however, experimental evidence is rather inconsistent. The beneficial effect of nanoconfinement on ( $\mathrm{La}, \mathrm{Sr}) \mathrm{CoO}_{3}$ (LSC) has been recently reported in $\mathrm{LSC}-(\mathrm{Ce}, \mathrm{Gd}) \mathrm{O}_{2}$ epitaxial heterostructures [294]. For LSC, there is a thermodynamic driving force to segregate $\mathrm{CoO}$ from the $\mathrm{La}_{2} \mathrm{O}_{3}$ components, especially when it chemically interacts with $\mathrm{CO}_{2}$ and water ${ }^{[267]}$. The degradation of $\mathrm{ABO}_{3}$ perovskites to $\mathrm{AO}-\mathrm{BO}$ can be suppressed in this case by nanoconfined heterostructures. Interestingly, this effect occurs by preserving the symmetry, even under large strain conditions where other phases are expected.

\section{Pathways towards metastability: a perspective on the design criteria}


As highlighted in the previous sections, there are multiple ways to achieve metastability in metal oxide interfaces. In this section, we discuss our vision for possible design criteria that, starting from the discussed experimental cases of the metal oxide interfaces, can harmonize the use of material simulations with advanced synthetic processes for an accelerates discovery of pathways towards metastability.

\subsection{Design by defects}

For bulk metal oxides, the combination of defects and dopants is often the privileged route for stabilizing metastable phases (e.g., Y, Ca, Sc, and Mg substitution or oxygen vacancies to stabilize cubic zirconia). An example of stabilization through vacancies is shown in Figure 11 for $\mathrm{Bi}_{2} \mathrm{O}_{3}$. The $\alpha$-phase of $\mathrm{Bi}_{2} \mathrm{O}_{3}$, the Gibbs phase, is the ground state in absence of defects/dopants and when no vacancies are present. DFT calculations show that increasing the number of vacancies has the effect of stabilizing the $\delta$-phase, as reported also experimentally ${ }^{[127,277,278]}$. Computer simulations have the potential to indicate how to dope a (bulk) material to increase its thermodynamic stability and physical vapour deposition methods are then able to finely control the assembly at the nanoscale, to introduce the desired concentration of dopants/defects into the structures ${ }^{[225]}$. Although the computational cost is still rather high, we are approaching a point where high-throughput defect calculations ${ }^{[68]}$ and stabilization of metastable phases through defects will become feasible. Modelling the low concentration limit of defects, as often found in nanomaterials, is rather trivial. Conversely, the high concentration situation can be quite challenging because some materials exhibit clustering of defects/vacancies and others tend to maximize the distance between them and artificial intelligence techniques might be used to address this issue ${ }^{[295]}$.

\subsection{Design by strain}


Several experimental cases show that strain becomes a key player in inducing polymorphisms and metastability. Interfaces are the stress/strain conditions that are normally exchanged and tuned from one material to another. To complete such design criteria, it is necessary to predict how polymorphs change their energy as they are strained, also beyond their bulk form as it have been recently done for $\mathrm{SrTiO}_{3}{ }^{[296]}$ and $\mathrm{LaTiO}_{2} \mathrm{~N}^{[297]}$. Computationally, this objective is achievable, but it is necessary to expand our current databases to include the energetics of materials under different strain conditions and to combine them with some of the tools mentioned in section 2. As an operative example, Figure 12 shows the energy with respect to the ground state of the three most common polymorphs of titania. The energy of anatase at large compressive or tensile strain (in the x-direction) is higher than that of unstrained brookite.

For low-energy transformations in highly dense polymorphs, the pathway is rather clear, as strained Gibbs phases may be equivalent to or even more energetic than relaxed metastable ones. This is shown in Figure 12, where strained anatase is energetically equivalent and even more energetic than relaxed and strained brookite over a wide range of strains. On the other hand, high-energy transformations seem not to be achievable by the mere effect of strain, as the energetic values induced by the strained lattice remain low. In the extreme case, highly strained configurations reach the breaking point of plastic deformation, bringing disorder and extensive defect arrangements in most metal oxides (Figure 7).

Furthermore, the minimal experimental evidence reported so far suggests that the concurrence of other effects together with the already discussed strain and defects, such as broken symmetry and nanoconfinement, would have to occur to allow high-energy transitions.

\subsection{Design by tailored elemental diffusion}

Elemental diffusion is the way materials assemble structures and microstructures from the atomic scale to the macroscale. Classical nucleation and growth theory remains the solid basis to theoretically model nanomaterials, including mass diffusion-related phenomena and 
solid-solid phase transformations. These occurrences can be included in the predictions with various degrees of accuracy. Moreover, the implementation of classical models via ab initio methods can establish structures under different conditions and visualize nanomaterials in a quantitative manner, generating nanoscale properties for different applications ${ }^{[298]}$.

As discussed in section 3, elemental diffusion in metal oxides is mainly controlled by cation mobility and defects in the lattice. Moreover, although some exceptions are possible ${ }^{[299]}$, surfaces and interfaces are the preferential paths to enhance cation mobility (see Figure 5). Interfaces can thus be a tool to increase mass diffusion and push polymorphism towards full metastability or towards the boundary of coexistence for both low- and high-energy transformations.

Figure 13 shows cation self-diffusion at the lattice and the interface in relation to the calculated free energy for $\mathrm{Bi}_{2} \mathrm{O}_{3}, \mathrm{TiO}_{2}$ and $\mathrm{Al}_{2} \mathrm{O}_{3}$, which possess high-density polymorphisms and cover a wide range of diffusivity, from low cation diffusion (in $\mathrm{Al}_{2} \mathrm{O}_{3}$ ) to high mobility (in $\mathrm{Bi}_{2} \mathrm{O}_{3}$ ). For a fixed thermal energy level (at $1000 \mathrm{~K}$ in Figure 13), we can distinguish two regions:

(i) the dominant lattice regime (dark blue), where the cation diffusion is large and surface diffusion is minor, and

(ii) the interface regime (light blue area), where the cation diffusion is sufficiently small that it occurs at the interface only, not in the lattice.

$\mathrm{Bi}_{2} \mathrm{O}_{3}$ belongs to the region (i), where the highly diffusive and phase changes can freely occur via the lattice configuration, and $\mathrm{Al}_{2} \mathrm{O}_{3}$, which is rather inert and no transformation is expected, belongs to (ii). As an intermediate case, $\mathrm{TiO}_{2}$ can have phase transformations ruled by lattice diffusion and others, where the transformation is expected to occur only at the interface.

Notably, both cation and interface self-diffusion depend on many factors, including structure (polymorphism), pressure, and other external conditions. To avoid this, another way to represent the diffusive effect can be to refer to the sole energetics factors including the 
energetic barrier to cation diffusion rather than the diffusion coefficient at fixed temperatures. In addition, the definition of the two areas is purely based on experimental experience rather than on an analytical expression.

The key role of computational tools here lies in the determination of the diffusion coefficients for polymorphic structures, at the lattices ${ }^{[300,301]}$ and interfaces levels. Such an approach requires a protocol to investigate surfaces, defects and vacancies in an autonomous way as well as a precise prediction of the "true" polymorphs and the elaboration of reliable energy and diffusive landscapes that consistently could represent the actual solid-state chemistry of materials and interfaces. Moreover, since several energetic factors interact simultaneously, e.g., cation diffusion is affected by defects, dopants, etc., it is necessary to define suitable boundary conditions to incorporate the dominant effects that are expected at the interface and, at the same time, to keep a reasonable computational cost. Experimentally, fine synthetic methods that can provide control over small changes during the synthesis also require effective characterization tools, e.g., in situ techniques, to obtain a full understanding of the metastability kinetics.

These considerations are mostly valid for single metal oxide materials. The situation is much more complex for other systems, such as $\mathrm{LiMO}_{2}$ and other materials commonly used as intercalation electrodes in batteries, in which the diffusivity of Li strongly depends on the crystal structure ${ }^{[302]}$. For these cases, different values for the diffusion of cations, which are now dependent on both structure and composition, should be plotted on the y-axis of Figure 13. For heteromaterial interfaces, fast diffusion through the interface, from a material to another, can lead to instability of the pristine compounds with formation of additional phases and interfaces. The resulting compounds from the elemental intermixing at the interface have generally a separate thermodynamic field of stability that can be treated individually. ${ }^{[283,284,293]}$ 
Further energetic effect from lattice strain can also be introduced in the analysis as, notoriously, strain can directly influence mass diffusion coefficients and diffusive pathways at the interface. ${ }^{[303]}$

\section{Conclusive Remarks}

Metastability in metal oxides finds a preferential field of existence at interfaces and at the nanoscale, bringing unexpected functionalities and novel technological solutions.

The intricate interplay between different energetic factors, such as nanoscale effects, presence of defects, lattice strain and elemental diffusion, leads to phase transformations and polymorphisms. A controlled design of metastable phases is thus challenging to achieve.

For the definition of general criteria and methods to establish metastability at the interface, a clear map of possible energy landscapes is strictly necessary. Useful tools have been proposed based on a synergy of materials modelling, from quantum mechanical to classical models, and experimental results. To achieve a complete design and control of metastability, it is necessary to establish, at the experimental level, fabrication and characterization protocols for highly quality nanostructures, allowing fine control of the material assembly, defect chemistry and microstructural and compositional homogeneity at the nanoscale level. At the computational level, the use of artificial intelligence and advanced models, able to discern small energy differences and metastability pathways, as well as extended databases, which include surfaces and non-equilibrium conditions, are expected to complete the picture and accelerate the stabilization of metastable configurations.

\section{Computational Methods}

The calculations included in Figure 12 were performed using the ASE and GPAW codes ${ }^{[304-306]}$ and PBEsol ${ }^{[307]}$ as the exchange-correlation functional to fully relax the investigated structures. Because of the small energy differences involved, the calculations for Figure 13 have 
been performed using VASP ${ }^{[308]}$ and SCAN as the exchange-correlation functional ${ }^{[48]}$. The input structures were obtained from the Materials Project database ${ }^{[309]}$, and they were fully relaxed until the forces were under $10 \mathrm{meV} / \AA$ while keeping the lattice parameter along the $\mathrm{x}$ direction constant. A k-point density of 3 kpoints/Å was used. The data used for Figure 2 and Figure 11 were obtained directly from the Materials Project database. Crystal structures were plotted using the VESTA3 package ${ }^{[310]}$.

\section{Acknowledgements}

VE would like to thank the Danish Council for Independent Research, Technology and Production Sciences Project 2 (grant no. 48293) for supporting this work. IEC acknowledges support from the Department of Energy Conversion and Storage, Technical University of Denmark, through the Special Competence Initiative "Autonomous Materials Discovery (AiMade)".

Received: ((will be filled in by the editorial staff))

Revised: ((will be filled in by the editorial staff)) Published online: ((will be filled in by the editorial staff))

\section{References}

[1] Z. Li, K. G. Pradeep, Y. Deng, D. Raabe, C. C. Tasan, Nature 2016, 534, 227.

[2] T. F. Kuech, S. E. Babcock, L. Mawst, Appl. Phys. Rev. 2016, 3, 040801.

[3] L. C. Seitz, C. F. Dickens, K. Nishio, Y. Hikita, J. Montoya, A. Doyle, C. Kirk, A. Vojvodic, H. Y. Hwang, J. K. Norskov, T. F. Jaramillo, Science (80-. ). 2016, 353, 1011.

[4] P. E. Pearce, A. J. Perez, G. Rousse, M. Saubanère, D. Batuk, D. Foix, E. McCalla, A. M. Abakumov, G. Van Tendeloo, M. L. Doublet, J. M. Tarascon, Nat. Mater. 2017, 16, 580.

[5] R. J. Davey, Cryst. Growth Des. 2002, 2, 675.

[6] C. Ehli, C. Oelsner, D. M. Guldi, A. Mateo-Alonso, M. Prato, C. Schmidt, C. Backes, F. Hauke, A. Hirsch, Nat. Chem. 2009, 1, 243. 
[7] W. Cai, J. Yu, M. Jaroniec, J. Mater. Chem. 2010, 20, 4587.

[8] S. Feng, R. Xu, Acc. Chem. Res. 2001, 34, 239.

[9] N. Blagden, M. de Matas, P. T. Gavan, P. York, Adv. Drug Deliv. Rev. 2007, 59, 617.

[10] D. V. Christensen, Y. Chen, V. Esposito, N. Pryds, APL Mater. 2019, 7, 0.

[11] N. Pryds, V. Esposito, J. Electroceramics 2017, 38, 1.

[12] B. P. Uberuaga, P. P. Dholabhai, G. Pilania, A. Chen, APL Mater. 2019, 7, 100904.

[13] A. Chen, Q. Su, H. Han, E. Enriquez, Q. Jia, Adv. Mater. 2019, 31, 1803241.

[14] H. L. Tuller, J. Electroceramics 1997, 1, 211.

[15] W. Sun, S. T. Dacek, S. P. Ong, G. Hautier, A. Jain, W. D. Richards, A. C. Gamst, K. A. Persson, G. Ceder, Sci. Adv. 2016, 2, e1600225.

[16] “Center for Next Generation of Materials Design: An Energy Frontier Research Center," can be found under https://www.cngmd-efrc.org/, n.d.

[17] M. Aykol, S. S. Dwaraknath, W. Sun, K. A. Persson, Sci. Adv. 2018, 4, 1.

[18] C. Giannini, E. Carlino, P. D. Cozzoli, R. Buonsanti, R. Cingolani, T. Kipp, V. Grillo, J. Am. Chem. Soc. 2008, 130, 11223.

[19] S. Shukla, S. Seal, Int. Mater. Rev. 2005, 50, 45.

[20] R. André, F. Natálio, M. Humanes, J. Leppin, K. Heinze, R. Wever, H. C. Schröder, W. E. G. Müller, W. Tremel, Adv. Funct. Mater. 2011, 21, 501.

[21] D. Ochs, W. Maus-Friedrichs, M. Brause, J. Günster, V. Kempter, V. Puchin, A. Shluger, L. Kantorovich, Surf. Sci. 1996, 365, 557.

[22] G. Klingelhöfer, R. V Morris, B. Bernhardt, C. Schröder, D. S. Rodionov, P. A. de Souza, A. Yen, R. Gellert, E. N. Evlanov, B. Zubkov, J. Foh, U. Bonnes, E. Kankeleit, P. Gütlich, D. W. Ming, F. Renz, T. Wdowiak, S. W. Squyres, R. E. Arvidson, Science 2004, 306, 1740.

[23] J. E. Rodríguez-Paéz, A. C. Caballero, M. Villegas, C. Moure, P. Durán, J. F. Fernández, J. Eur. Ceram. Soc. 2001, 21, 925. 
[24] S. S. Mao, P. E. Burrows, J. Mater. 2015, 1, 85.

[25] V. Tshitoyan, J. Dagdelen, L. Weston, A. Dunn, Z. Rong, O. Kononova, K. A. Persson, G. Ceder, A. Jain, Nature 2019, 571, 95.

[26] R. Schmitt, J. Spring, R. Korobko, J. L. M. Rupp, ACS Nano 2017, 11, 8881.

[27] W. W. Zhan, Q. Kuang, J. Z. Zhou, X. J. Kong, Z. X. Xie, L. S. Zheng, J. Am. Chem. Soc. 2013, 135, 1926.

[28] R. O. Jones, Rev. Mod. Phys. 2015, 87, DOI 10.1103/RevModPhys.87.897.

[29] K. Alberi, M. B. Nardelli, A. Zakutayev, L. Mitas, S. Curtarolo, A. Jain, M. Fornari, N. Marzari, I. Takeuchi, M. L. Green, M. Kanatzidis, M. F. Toney, S. Butenko, B.

Meredig, S. Lany, U. Kattner, A. Davydov, E. S. Toberer, V. Stevanovic, A. Walsh, N. G. Park, A. Aspuru-Guzik, D. P. Tabor, J. Nelson, J. Murphy, A. Setlur, J. Gregoire, H. Li, R. Xiao, A. Ludwig, L. W. Martin, A. M. Rappe, S. H. Wei, J. Perkins, The 2019 Materials by Design Roadmap, 2019.

[30] S. Curtarolo, G. L. W. Hart, M. B. Nardelli, N. Mingo, S. Sanvito, O. Levy, Nat. Mater. 2013, 12, 191.

[31] "Inorganic Crystal Structure Database," can be found under https://icsd.fizkarlsruhe.de, n.d.

[32] "Springer Materials," can be found under https://materials.springer.com/, n.d.

[33] A. Zakutayev, N. Wunder, M. Schwarting, J. D. Perkins, R. White, K. Munch, W. Tumas, C. Phillips, Sci. Data 2018, 5, 180053.

[34] “The Materials Project," can be found under https://materialsproject.org/, n.d.

[35] “The Open Quantum Materials Database,” can be found under https://oqmd.org, n.d.

[36] “Automatic - FLOW for Materials Discovery," can be found under http://aflowlib.org/, n.d.

[37] "Materials Cloud," can be found under https://www.materialscloud.org/, n.d.

[38] “NREL Materials Database," can be found under https://materials.nrel.gov/, n.d. 
[39] "The Computational Materials Repository (CMR)," can be found under https://cmr.fysik.dtu.dk/, n.d.

[40] A. Kumar, Am. J. Nano Res. Appl. 2018, 6, 1.

[41] A. Fujishima, K. Honda, Nature 1972, 238, 37.

[42] K. Hashimoto, H. Irie, A. Fujishima, Jpn. J. Appl. Phys. 2005, 44, 8269.

[43] J. Buckeridge, K. T. Butler, C. R. A. Catlow, A. J. Logsdail, D. O. Scanlon, S. A. Shevlin, S. M. Woodley, A. A. Sokol, A. Walsh, Chem. Mater. 2015, 27, 3844.

[44] J. P. Perdew, K. Burke, M. Ernzerhof, Phys. Rev. Lett. 1996, 77, 3865.

[45] M. T. Curnan, J. R. Kitchin, J. Phys. Chem. C 2015, 119, 21060.

[46] S. L. Dudarev, G. A. Botton, S. Y. Savrasov, C. J. Humphreys, A. P. Sutton, Phys. Rev. $B$ 1998, 57, 1505 .

[47] J. Heyd, G. E. Scuseria, M. Ernzerhof, J. Chem. Phys. 2003, 118, 8207.

[48] J. Sun, R. C. Remsing, Y. Zhang, Z. Sun, A. Ruzsinszky, H. Peng, Z. Yang, A. Paul, U. Waghmare, X. Wu, M. L. Klein, J. P. Perdew, Nat. Chem. 2016, 8, 831.

[49] J. Wellendorff, K. T. Lundgaard, A. Møgelhøj, V. Petzold, D. D. Landis, J. K. Nørskov, T. Bligaard, K. W. Jacobsen, Phys. Rev. B 2012, 85, 235149.

[50] K. T. Butler, J. M. Frost, J. M. Skelton, K. L. Svane, A. Walsh, Chem. Soc. Rev. 2016, $45,6138$.

[51] S. M. Woodley, P. D. Battle, J. D. Gale, C. Richard A. Catlow, Phys. Chem. Chem. Phys. 1999, 1, 2535.

[52] A. R. Oganov, C. W. Glass, J. Chem. Phys. 2006, 124, DOI 10.1063/1.2210932.

[53] I. E. Castelli, T. Olsen, S. Datta, D. D. Landis, S. Dahl, K. S. Thygesen, K. W. Jacobsen, Energy Environ. Sci. 2012, 5, 5814.

[54] C. J. Pickard, R. J. Needs, J. Phys. Condens. Matter 2011, 23, DOI 10.1088/09538984/23/5/053201.

[55] V. Stevanović, Phys. Rev. Lett. 2016, 116, 1. 
[56] J. Pannetier, J. Bassas-Alsina, J. Rodriguez-Carvajal, V. Caignaert, Nature 1990, 346, 343.

[57] A. Laio, M. Parrinello, Proc. Natl. Acad. Sci. U. S. A. 2002, 99, 12562.

[58] A. Barducci, M. Bonomi, M. Parrinello, Wiley Interdiscip. Rev. Comput. Mol. Sci. 2011, $1,826$.

[59] S. Goedecker, J. Chem. Phys. 2004, 120, 9911.

[60] D. J. Wales, J. P. K. Doye, J. Phys. Chem. A 1997, 101, 5111.

[61] C. C. Fischer, K. J. Tibbetts, D. Morgan, G. Ceder, Nat. Mater. 2006, 5, 641.

[62] V. Stevanović, R. Trottier, C. Musgrave, F. Therrien, A. Holder, P. Graf, Phys. Rev. Mater. 2018, 2, 033802.

[63] C. J. Bartel, S. L. Millican, A. M. Deml, J. R. Rumptz, W. Tumas, A. W. Weimer, S. Lany, V. Stevanović, C. B. Musgrave, A. M. Holder, Nat. Commun. 2018, 9, DOI 10.1038/s41467-018-06682-4.

[64] M. Aykol, V. I. Hegde, L. Hung, S. Suram, P. Herring, C. Wolverton, J. S. Hummelshøj, Nat. Commun. 2019, 10, 1.

[65] P. A. Schultz, Phys. Rev. Lett. 2006, 96, 246401.

[66] C. G. Van de Walle, J. Neugebauer, J. Appl. Phys. 2004, 95, 3851.

[67] R. Ramprasad, H. Zhu, P. Rinke, M. Scheffler, Phys. Rev. Lett. 2012, 108, 066404.

[68] A. Goyal, P. Gorai, H. Peng, S. Lany, V. Stevanović, Comput. Mater. Sci. 2017, 130, 1.

[69] D. Broberg, B. Medasani, N. E. R. Zimmermann, G. Yu, A. Canning, M. Haranczyk, M. Asta, G. Hautier, Comput. Phys. Commun. 2018, 226, 165.

[70] S. K. Wallace, K. P. McKenna, Adv. Mater. Interfaces 2014, 1, 1400078.

[71] P. J. Shamberger, J. L. Wohlwend, A. K. Roy, A. A. Voevodin, J. Phys. Chem. C 2016, $120,13049$.

[72] W. Körner, C. Elsässer, Phys. Rev. B 2011, 83, 205315.

[73] W. T. Read, W. Shockley, Phys. Rev. 1950, 78, 275. 
[74] M. R. Fellinger, A. M. Z. Tan, L. G. Hector, D. R. Trinkle, Phys. Rev. Mater. 2018, 2, 113605.

[75] K. Kaur, C. V. Singh, Energy Procedia 2012, 29, 291.

[76] M. Matsui, M. Akaogi, Mol. Simul. 1991, 6, 239.

[77] E. Chagarov, A. C. Kummel, in ECS Trans., ECS, 2008, pp. 773-785.

[78] R. Yamamoto, C. Bell, Y. Hikita, H. Y. Hwang, H. Nakamura, T. Kimura, Y. Wakabayashi, Phys. Rev. Lett. 2011, 107, 036104.

[79] R. A. Evarestov, A. V. Bandura, V. E. Alexandrov, Surf. Sci. 2007, 601, 1844.

[80] X. Tian, T. Wang, L. Fan, Y. Wang, H. Lu, Y. Mu, Appl. Surf. Sci. 2018, 427, 357.

[81] M. Zschornak, S. Gemming, E. Gutmann, T. Weißbach, H. Stöcker, T. Leisegang, T. Riedl, M. Tränkner, T. Gemming, D. C. Meyer, Acta Mater. 2010, 58, 4650.

[82] K. Reuter, M. Scheffler, Phys. Rev. B 2001, 65, 035406.

[83] N. Nilius, H. Fedderwitz, B. Groß, C. Noguera, J. Goniakowski, Phys. Chem. Chem. Phys. 2016, 18, 6729.

[84] G. Geneste, B. Dkhil, Phys. Rev. B 2009, 79, 235420.

[85] K. A. Persson, B. Waldwick, P. Lazic, G. Ceder, Phys. Rev. B 2012, 85, 235438.

[86] I. E. Castelli, K. S. Thygesen, K. W. Jacobsen, Top. Catal. 2014, 57, 265.

[87] A. M. Patel, J. K. Nørskov, K. A. Persson, J. H. Montoya, Phys. Chem. Chem. Phys. 2019, 21, 25323.

[88] A. K. Singh, L. Zhou, A. Shinde, S. K. Suram, J. H. Montoya, D. Winston, J. M. Gregoire, K. A. Persson, Chem. Mater. 2017, 29, 10159.

[89] D. F. Abbott, R. K. Pittkowski, K. Macounová, R. Nebel, E. Marelli, E. Fabbri, I. E. Castelli, P. Krtil, T. J. Schmidt, ACS Appl. Mater. Interfaces 2019, 11, 37748.

[90] B.-J. Kim, E. Fabbri, I. Castelli, M. Borlaf, T. Graule, M. Nachtegaal, T. Schmidt, Catalysts 2019, 9, 263.

[91] B.-J. Kim, X. Cheng, D. F. Abbott, E. Fabbri, F. Bozza, T. Graule, I. E. Castelli, L. 
Wiles, N. Danilovic, K. E. Ayers, N. Marzari, T. J. Schmidt, Adv. Funct. Mater. 2018, $28,1804355$.

[92] A. Bagger, I. E. Castelli, M. H. Hansen, J. Rossmeisl, in Handb. Mater. Model., Springer International Publishing, Cham, 2018, pp. 1-31.

[93] W. Sun, S. Jayaraman, W. Chen, K. A. Persson, G. Ceder, Proc. Natl. Acad. Sci. 2015, $112,3199$.

[94] D. A. Kitchaev, G. Ceder, Nat. Commun. 2016, 7, 13799.

[95] P. Mehta, P. A. Salvador, J. R. Kitchin, ACS Appl. Mater. Interfaces 2014, 6, 3630.

[96] A. Zur, T. C. McGill, J. Appl. Phys. 1984, 55, 378.

[97] K. T. Butler, C. H. Hendon, A. Walsh, Faraday Discuss. 2017, 201, 207.

[98] K. Mathew, A. K. Singh, J. J. Gabriel, K. Choudhary, S. B. Sinnott, A. V. Davydov, F. Tavazza, R. G. Hennig, Comput. Mater. Sci. 2016, 122, 183.

[99] H. Ding, S. S. Dwaraknath, L. Garten, P. Ndione, D. Ginley, K. A. Persson, ACS Appl. Mater. Interfaces 2016, 8, 13086.

[100] S. Choi, S. J. Chang, J. Oh, J. H. Jang, S. Lee, Adv. Electron. Mater. 2018, 4, 1.

[101] B. Singh, B. Ghosh, C. Su, H. Lin, A. Agarwal, A. Bansil, Phys. Rev. Lett. 2018, 121, 226401.

[102] L. M. Garten, S. Dwaraknath, J. Walker, J. S. Mangum, P. F. Ndione, Y. Park, D. A. Beaton, V. Gopalan, B. P. Gorman, L. T. Schelhas, M. F. Toney, S. Trolier-McKinstry, K. A. Persson, D. S. Ginley, Adv. Mater. 2018, 30, 1.

[103] P. Nieves, S. Arapan, J. Maudes-Raedo, R. Marticorena-Sánchez, N. L. Del Brío, A. Kovacs, C. Echevarria-Bonet, D. Salazar, J. Weischenberg, H. Zhang, O. Y. Vekilova, R. Serrano-López, J. M. Barandiaran, K. Skokov, O. Gutfleisch, O. Eriksson, H. C. Herper, T. Schrefl, S. Cuesta-López, Comput. Mater. Sci. 2019, 168, 188.

[104] J. J. Plata, J. A. Su, M. M. Antonio, J. F. Sanz, 2019, 1.

[105] Z. Xu, P. Salvador, J. R. Kitchin, ACS Appl. Mater. Interfaces 2017, 9, 4106. 
[106] A. S. M. Jonayat, S. Chen, A. C. T. Van Duin, M. Janik, Langmuir 2018, 34, 11685.

[107] S. Surnev, G. Kresse, M. G. Ramsey, F. P. Netzer, Phys. Rev. Lett. 2001, 87, 861021.

[108] S. K. Yadav, S. Shao, J. Wang, X. Y. Liu, Sci. Rep. 2015, 5, 1.

[109] J. Zimmermann, M. W. Finnis, L. C. Ciacchi, J. Chem. Phys. 2009, 130, DOI $10.1063 / 1.3105992$.

[110] A. Vittadini, F. Sedona, S. Agnoli, L. Artiglia, M. Casarin, G. A. Rizzi, M. Sambi, G. Granozzi, ChemPhysChem 2010, 11, 1550.

[111] W. B. Jackson, R. Hoffman, B. Yeh, T. Emery, T. Koch, C. McConica, O. Kwon, Phys. Status Solidi Appl. Mater. Sci. 2010, 207, 695.

[112] H. Hori, K. Tanaka, Y. Oda, T. Minemoto, H. Takakura, J. Cryst. Growth 2009, 311, 727.

[113] L. Bakaleinikov, A. Gordon, Phys. B Condens. Matter 2010, 405, 1207.

[114] A. Mittiga, F. Biccari, C. Malerba, Thin Solid Films 2009, 517, 2469.

[115] S. Georges, M. Salaün, Solid State Ionics 2008, 178, 1898.

[116] L. D. Burke, N. S. Naser, J. Appl. Electrochem. 2005, 35, 931.

[117] R. H. R. Castro, R. B. Tǒrres, G. J. Pereira, D. Gouvěa, Chem. Mater. 2010, 22, 2502.

[118] M. H. Park, Y. H. Lee, H. J. Kim, Y. J. Kim, T. Moon, K. Do Kim, S. D. Hyun, T. Mikolajick, U. Schroeder, C. S. Hwang, Nanoscale 2018, 10, 716.

[119] W. N. Zhao, S. C. Zhu, Y. F. Li, Z. P. Liu, Chem. Sci. 2015, 6, 3483.

[120] Q. Fu, F. Yang, X. Bao, Acc. Chem. Res. 2013, 46, 1692.

[121] T. Ito, Jpn. J. Appl. Phys. 1992, 31, L920.

[122] D. G. Gregory, L. Lu, C. J. Kiely, M. A. Snyder, J. Phys. Chem. C 2017, 121, 4434.

[123] Y. Ning, M. Wei, L. Yu, F. Yang, R. Chang, Z. Liu, Q. Fu, X. Bao, J. Phys. Chem. C 2015, 119, 27556.

[124] Z. Gao, Y. Qin, Acc. Chem. Res. 2017, 50, 2309.

[125] C. J. Wang, D. J. Liu, J. W. Evans, J. Chem. Phys. 2015, 142, DOI 10.1063/1.4918908. 
[126] T. Nozaki, H. Kubota, A. Fukushima, S. Yuasa, Appl. Phys. Lett. 2015, 106, 1.

[127] D. L. Proffit, G. R. Bai, D. D. Fong, T. T. Fister, S. O. Hruszkewycz, M. J. Highland, P. M. Baldo, P. H. Fuoss, T. O. Mason, J. A. Eastman, Appl. Phys. Lett. 2010, 96, 1.

[128] J.-C. Huang, Y.-H. Shih, S. Lirio, S.-Y. Wu, H.-T. Chen, W.-L. Liu, C.-H. Lin, H.-Y. Huang, Chem. Commun. 2019, 55, 4475.

[129] F. Haque, T. Daeneke, K. Kalantar-zadeh, J. Z. Ou, Nano-Micro Lett. 2018, 10, 23.

[130] X. Guan, X. Shen, W. Wang, W. Wang, Q. Lan, J. J. Zhang, J. J. Zhang, H. Yang, Y. Yao, J. Li, C. Gu, J. Sun, R. Yu, Inorg. Chem. 2019, acs. inorgchem.9b02326.

[131] Z. Ma, F. Jing, Y. Fan, L. Hou, L. Su, L. Fan, G. Shao, Small 2019, 15, 1900862.

[132] J. Chakhalian, J. W. Freeland, A. J. Millis, C. Panagopoulos, J. M. Rondinelli, Rev. Mod. Phys. 2014, 86, DOI 10.1103/RevModPhys.86.1189.

[133] K. D. Fredrickson, A. A. Demkov, Phys. Rev. B - Condens. Matter Mater. Phys. 2015, $91,1$.

[134] R. Ferrando, G. Rossi, F. Nita, G. Barcaro, A. Fortunelli, ACS Nano 2008, 2, 1849.

[135] H. Y. Hwang, Y. Iwasa, M. Kawasaki, B. Keimer, N. Nagaosa, Y. Tokura, Nat. Mater. 2012, 11, 103.

[136] U. Herr, Contemp. Phys. 2000, 41, 93.

[137] J. Liu, Q. Li, T. Wang, D. Yu, Y. Li, Angew. Chemie - Int. Ed. 2004, 43, 5048.

[138] L. D. Gelb, K. E. Gubbins, R. Radhakrishnan, M. Sliwinska-Bartkowiak, Reports Prog. Phys. 1999, 62, 1573.

[139] M. Souri, J. H. Gruenewald, J. Terzic, J. W. Brill, G. Cao, S. S. A. Seo, Sci. Rep. 2016, $6,25967$.

[140] B. Rupp, J. Less Common Met. 1984, 104, 51.

[141] A. Muñoz, M. T. Casáis, J. A. Alonso, M. J. Martínez-Lope, J. L. Martínez, M. T. Fernández-Díaz, Inorg. Chem. 2001, 40, 1020.

[142] A. D. Polli, F. F. Lange, C. G. Levi, J. Am. Ceram. Soc. 2004, 83, 873. 
[143] Y. Duan, S. Sun, Y. Sun, S. Xi, X. Chi, Q. Zhang, X. Ren, J. Wang, S. J. H. Ong, Y. Du, L. Gu, A. Grimaud, Z. J. Xu, Adv. Mater. 2019, 31, 1807898.

[144] J. M. A. Beattie, J. P. Goss, M. J. Rayson, P. R. Briddon, Diam. Relat. Mater. 2019, 94, 137.

[145] F. Lin, I. M. Markus, D. Nordlund, T.-C. Weng, M. D. Asta, H. L. Xin, M. M. Doeff, Nat. Commun. 2014, 5, 3529.

[146] M. Xu, S. Shao, B. Gao, J. Lv, Q. Li, Y. Wang, H. Wang, L. Zhang, Y. Ma, ACS Appl. Mater. Interfaces 2017, 9, 7891.

[147] V. H. Grassian, J. Phys. Chem. C 2008, 112, 18303.

[148] M. I. Osendi, J. S. Moya, C. J. Serna, J. Soria, J. Am. Ceram. Soc. 1985, 68, 135.

[149] N. Satoh, T. Nakashima, K. Yamamoto, Sci. Rep. 2013, 3, DOI 10.1038/srep01959.

[150] J. Baumgartner, A. Dey, P. H. H. Bomans, C. Le Coadou, P. Fratzl, N. A. J. M. Sommerdijk, D. Faivre, Nat. Mater. 2013, 12, 310.

[151] A. Navrotsky, L. Mazeina, J. Majzlan, Science (80-. ). 2008, 319, 1635.

[152] U. I. Gaya, A. H. Abdullah, J. Photochem. Photobiol. C Photochem. Rev. 2008, 9, 1.

[153] M. K. Nazeeruddin, A. Kay, I. Rodicio, R. Humphry-Baker, E. Müller, P. Liska, N. Vlachopoulos, M. Grätzel, J. Am. Chem. Soc. 1993, 115, 6382.

[154] Y. K. Kho, A. Iwase, W. Y. Teoh, L. Mädler, A. Kudo, R. Amal, J. Phys. Chem. C 2010, 114, 2821.

[155] L. Cao, D. Chen, W. Li, R. A. Caruso, ACS Appl. Mater. Interfaces 2014, 6, 13129.

[156] B. Liu, A. Khare, E. S. Aydil, ACS Appl. Mater. Interfaces 2011, 3, 4444.

[157] A. Di Paola, M. Bellardita, R. Ceccato, L. Palmisano, F. Parrino, J. Phys. Chem. C 2009, 113, 15166.

[158] K. C. Ko, S. T. Bromley, J. Y. Lee, F. Illas, J. Phys. Chem. Lett. 2017, 8, 5593.

[159] S. C. Zhu, S. H. Xie, Z. P. Liu, J. Am. Chem. Soc. 2015, 137, 11532.

[160] A. A. Gribb, J. F. Banfield, Am. Mineral. 1997, 82, 717. 
[161] G. Guenther, R. Theissmann, O. Guillon, J. Phys. Chem. C 2014, 118, 27020.

[162] B. R. Chen, W. Sun, D. A. Kitchaev, J. S. Mangum, V. Thampy, L. M. Garten, D. S. Ginley, B. P. Gorman, K. H. Stone, G. Ceder, M. F. Toney, L. T. Schelhas, Nat. Commun. 2018, 9, DOI 10.1038/s41467-018-04917-y.

[163] B. T. Holland, C. F. Blanford, T. Do, A. Stein, Chem. Mater. 1999, 11, 795.

[164] J. P. Jolivet, S. Cassaignon, C. Chanéac, D. Chiche, O. Durupthy, D. Portehault, Comptes Rendus Chim. 2010, 13, 40.

[165] R. L. Penn, J. F. Banfield, Am. Mineral. 1998, 83, 1077.

[166] W. Wu, Z. Wu, T. Yu, C. Jiang, W.-S. S. Kim, Sci. Technol. Adv. Mater. 2015, 16, 23501.

[167] S. Sood, P. Gouma, J. Am. Ceram. Soc. 2013, 96, 351.

[168] H. Tang, K. Prasad, R. Sanjinès, P. E. Schmid, F. Lévy, J. Appl. Phys. 1994, 75, 2042.

[169] J. Ye, W. Liu, J. Cai, S. Chen, X. Zhao, H. Zhou, L. Qi, J. Am. Chem. Soc. 2011, 133, 933.

[170] Q. Zhang, I. Lee, J. B. Joo, F. Zaera, Y. Yin, Acc. Chem. Res. 2013, 46, 1816.

[171] S. G. Kumar, L. G. Devi, J. Phys. Chem. A 2011, 115, 13211.

[172] H. Li, Z. Bian, J. Zhu, D. Zhang, G. Li, Y. Huo, H. Li, Y. Lu, J. Am. Chem. Soc. 2007, $129,8406$.

[173] G. Liu, L. Wang, H. G. Yang, H. M. Cheng, G. Q. Lu, J. Mater. Chem. 2010, 20, 831.

[174] M. Shang, W. Wang, L. Zhang, S. Sun, L. Wang, L. Zhou, J. Phys. Chem. C 2009, 113, 14727.

[175] W. Zhou, H. Liu, J. Wang, D. Liu, G. Du, J. Cui, ACS Appl. Mater. Interfaces 2010, 2 , 2385.

[176] L. Huang, F. Peng, H. Wang, H. Yu, Z. Li, Catal. Commun. 2009, 10, 1839.

[177] E. A. Barringei, H. K. Bowen, Langmuir 1985, 1, 414.

[178] G. Li, L. Chen, M. E. Graham, K. A. Gray, J. Mol. Catal. A Chem. 2007, 275, 30. 
[179] C. Trakanprapai, V. Esposito, S. Licoccia, E. Traversa, J. Mater. Res. 2005, 20, 128.

[180] D. Marani, R. H. Silva, A. Dankeaw, K. Norrman, R. M. L. Werchmeister, D. Ippolito, M. Gudik-Sørensen, K. K. Hansen, V. Esposito, New J. Chem. 2017, 41, 3466.

[181] P. D. Cozzoli, A. Kornowski, H. Weller, J. Am. Chem. Soc. 2003, 125, 14539.

[182] A. S. Barnard, R. R. Yeredla, H. Xu, Nanotechnology 2006, 17, 3039.

[183] R. L. Penn, J. F. Banfield, Geochim. Cosmochim. Acta 1999, 63, 1549.

[184] D. A. H. Hanaor, C. C. Sorrell, J. Mater. Sci. 2011, 46, 855.

[185] C. J. Tavares, S. M. Marques, L. Rebouta, S. Lanceros-Méndez, V. Sencadas, C. M. Costa, E. Alves, A. J. Fernandes, Thin Solid Films 2008, 517, 1161.

[186] M. Paulose, K. Shankar, O. K. Varghese, G. K. Mor, C. A. Grimes, J. Phys. D. Appl. Phys. 2006, 39, 2498.

[187] M. P. Moret, R. Zallen, D. P. Vijay, S. B. Desu, Thin Solid Films 2000, 366, 8.

[188] A. S. Barnard, H. Xu, ACS Nano 2008, 2, 2237.

[189] S. Liu, J. Yu, M. Jaroniec, Chem. Mater. 2011, 23, 4085.

[190] P. Biswas, M. Sahu, T. Charinpanitkul, J. Jiang, K. Suttiponparnit, S. Suvachittanont, Nanoscale Res. Lett. 2010, 1.

[191] R. Bliem, E. McDermott, P. Ferstl, M. Setvin, O. Gamba, J. Pavelec, M. A. Schneider, M. Schmid, U. Diebold, P. Blaha, L. Hammer, G. S. Parkinson, Science (80-. ). 2014, $346,1215$.

[192] K. Sabyrov, R. Lee Penn, CrystEngComm 2015, 17, 2062.

[193] S. Bakardjieva, V. Stengl, L. Szatmary, J. Subrt, J. Lukac, N. Murafa, D. Niznansky, K. Cizek, J. Jirkovsky, N. Petrova, J. Mater. Chem. 2006, 16, 1709.

[194] P. Scheiber, M. Fidler, O. Dulub, M. Schmid, U. Diebold, W. Hou, U. Aschauer, A. Selloni, Phys. Rev. Lett. 2012, 109, 1.

[195] D. J. Reidy, J. D. Holmes, M. A. Morris, J. Eur. Ceram. Soc. 2006, 26, 1527.

[196] W. Li, C. Ni, H. Lin, C. P. Huang, S. I. Shah, J. Appl. Phys. 2004, 96, 6663. 
[197] C. Perego, R. Revel, O. Durupthy, S. Cassaignon, J.-P. Jolivet, Solid State Sci. 2010, $12,989$.

[198] B. A. Apgar, L. W. Martin, Cryst. Growth Des. 2014, 14, 1981.

[199] A. L. Da Silva, D. N. F. Muche, L. B. Caliman, J. Bettini, R. H. R. Castro, A. Navrotsky, D. Gouvêa, J. Phys. Chem. C 2019, 123, 4949.

[200] Y. Hu, H. L. Tsai, C. L. Huang, J. Eur. Ceram. Soc. 2003, 23, 691.

[201] T. Chraska, A. H. King, C. C. Berndt, Mater. Sci. Eng. A 2000, 286, 169.

[202] G. Baldinozzi, D. Simeone, D. Gosset, M. Dutheil, Phys. Rev. Lett. 2003, 90, 4.

[203] R. Nitsche, M. Rodewald, G. Skandan, H. Fuess, H. Hahn, Nanostructured Mater. 1996, 7, 535 .

[204] T. Hensl, U. Mühlich, M. Budnitzki, M. Kuna, Acta Mater. 2015, 86, 361.

[205] S. Heiroth, R. Ghisleni, T. Lippert, J. Michler, A. Wokaun, Acta Mater. 2011, 59, 2330.

[206] D. Baghmar, Phase Transitions 2013, 86, 811.

[207] J. C. Thomas, A. Van Der Ven, Phys. Rev. B 2017, 96, 1.

[208] H. Wang, Z. Wang, L. Liu, X. Gong, M. Wang, Cryst. Growth Des. 2016, 16, 1056.

[209] A. Navrotsky, Geochem. Trans. 2003, 4, 34.

[210] G. H. Mhlongo, D. E. Motaung, S. S. Nkosi, H. C. Swart, G. F. Malgas, K. T. Hillie, B. W. Mwakikunga, Appl. Surf. Sci. 2014, 293, 62.

[211] R. Rasoulkhani, H. Tahmasbi, S. A. Ghasemi, S. Faraji, S. Rostami, M. Amsler, Phys. Rev. B 2017, 96, 1.

[212] C. Wöll, Prog. Surf. Sci. 2007, 82, 55.

[213] Y. Sun, S. Jiang, W. Bi, R. Long, X. Tan, C. Wu, S. Wei, Y. Xie, Nanoscale 2011, 3, 4394.

[214] H. A. Harwig, A. G. Gerards, Thermochim. Acta 1979, 28, 121.

[215] B.-R. Chen, W. Sun, D. A. Kitchaev, J. S. Mangum, V. Thampy, L. M. Garten, D. G. 
Ginley, B. P. Gorman, K. H. Stone, G. Ceder, M. F. Toney, L. T. Schelhas, Microsc. Microanal. 2018, 24, 1486.

[216] S. Sood, P. Gouma, Nanomater. Energy 2013, 2, 82.

[217] G. D. Palkar, D. N. Sitharamarao, A. K. Dasgupta, Trans. Faraday Soc. 1963, 59, 2634.

[218] M. Shandalov, P. C. McIntyre, J. Appl. Phys. 2009, 106, 0.

[219] S. A. Eliziário, L. S. Cavalcante, J. C. Sczancoski, P. S. Pizani, J. A. Varela, J. W. M. Espinosa, E. Longo, Nanoscale Res. Lett. 2009, 4, 1371.

[220] P. Roy, S. Berger, P. Schmuki, Angew. Chemie - Int. Ed. 2011, 50, 2904.

[221] Z. R. Tian, J. A. Voigt, J. Liu, B. Mckenzie, M. J. Mcdermott, M. A. Rodriguez, H. Konishi, H. Xu, Nat. Mater. 2003, 2, 821.

[222] V. Esposito, D. W. Ni, D. Marani, F. Teocoli, K. T. S. Thydén, D. Z. De Florio, F. C. Fonseca, J. Mater. Chem. A 2016, 4, 16871.

[223] V. Esposito, E. Traversa, J. Am. Ceram. Soc. 2008, 91, 1037.

[224] D. Z. De Florio, V. Esposito, E. Traversa, R. Muccillo, F. C. Fonseca, J. Therm. Anal. Calorim. 2009, 97, 143.

[225] M. Raza, S. Sanna, L. Dos Santos Gómez, E. Gautron, A. A. El Mel, N. Pryds, R. Snyders, S. Konstantinidis, V. Esposito, Phys. Chem. Chem. Phys. 2018, 20, 26068.

[226] I. Perez, E. Robertson, P. Banerjee, L. Henn-Lecordier, S. J. Son, S. B. Lee, G. W. Rubloff, Small 2008, 4, 1223.

[227] V. Esposito, D. W. Ni, S. Sanna, F. Gualandris, N. Pryds, RSC Adv. 2017, 7, 13784.

[228] H. A. Harwig, A. G. Gerards, J. Solid State Chem. 1978, 26, 265.

[229] G. Guenther, F. E. Kruis, O. Guillon, J. Phys. Chem. C 2014, 118, 27010.

[230] A. V. Virkar, J. Electrochem. Soc. 2006, 138, 1481.

[231] E. D. Wachsman, G. R. Ball, N. Jiang, D. A. Stevenson, Solid State Ionics 1992, 52, 213. 
[232] M. J. Verkerk, G. M. H. van de Velde, A. J. Burggraaf, R. B. Helmholdt, J. Phys. Chem. Solids 1982, 43, 1129.

[233] R. Mazumder, S. Ghosh, P. Mondal, D. Bhattacharya, S. Dasgupta, N. Das, A. Sen, A. K. Tyagi, M. Sivakumar, T. Takami, H. Ikuta, J. Appl. Phys. 2006, 100, DOI 10.1063/1.2229667.

[234] O. V. Al'myasheva, E. N. Korytkova, A. V. Maslov, V. V. Gusarov, Inorg. Mater. 2005, 41,460 .

[235] S. Zhou, M. Antonietti, M. Niederberger, Small 2007, 3, 763.

[236] J. M. McHale, Science (80-. ). 1997, 277, 788.

[237] G. Paglia, C. E. Buckley, A. L. Rohl, R. D. Hart, K. Winter, A. J. Studer, B. A. Hunter, J. V. Hanna, Chem. Mater. 2004, 16, 220.

[238] J. Sánchez-Valente, F. Hernández-Beltrán, M. L. Guzman-Castillo, J. J. Fripiat, X. Bokhimi, J. Mater. Res. 2004, 19, 1499.

[239] Q. Fang, P. S. Sidky, M. G. Hocking, Wear 1999, 233-235, 615.

[240] Y. C. Kim, S. J. Lee, I.-K. Oh, S. Seo, H. Kim, J.-M. Myoung, J. Alloys Compd. 2016, 688, 1108.

[241] Y. L. Tang, Y. L. Zhu, Y. Liu, Y. J. Wang, X. L. Ma, Nat. Commun. 2017, 8, 15994.

[242] S. Sanna, V. Esposito, D. Pergolesi, A. Orsini, A. Tebano, S. Licoccia, G. Balestrino, E. Traversa, Adv. Funct. Mater. 2009, 19, 1713.

[243] K. M. Kant, V. Esposito, N. Pryds, Appl. Phys. Lett. 2010, 97, 5.

[244] J. Narayan, B. C. Larson, J. Appl. Phys. 2003, 93, 278.

[245] O. Y. Gorbenko, S. V. Samoilenkov, I. E. Graboy, A. R. Kaul, Chem. Mater. 2002, 14, 4026.

[246] A. Lotnyk, S. Senz, D. Hesse, Thin Solid Films 2007, 515, 3439.

[247] R. J. Kennedy, P. A. Stampe, J. Cryst. Growth 2003, 252, 333.

[248] M. Li, W. Hebenstreit, U. Diebold, M. A. Henderson, D. R. Jennison, Faraday 
Discuss. 1999, 114, 245.

[249] N. H. Vu, H. V. Le, T. M. Cao, V. V. Pham, H. M. Le, D. Nguyen-Manh, J. Phys. Condens. Matter 2012, 24, DOI 10.1088/0953-8984/24/40/405501.

[250] M. V. Ganduglia-Pirovano, A. Hofmann, J. Sauer, Surf. Sci. Rep. 2007, 62, 219.

[251] D. W. Ni, D. Z. De Florio, D. Marani, A. Kaiser, V. B. Tinti, V. Esposito, J. Mater. Chem. A 2015, 3, 18835.

[252] Z. Feng, Y. Yacoby, W. T. Hong, H. Zhou, M. D. Biegalski, H. M. Christen, Y. ShaoHorn, Energy Environ. Sci. 2014, 7, 1166.

[253] P. Yan, A. Nie, J. Zheng, Y. Zhou, D. Lu, X. Zhang, R. Xu, I. Belharouak, X. Zu, J. Xiao, K. Amine, J. Liu, F. Gao, R. Shahbazian-Yassar, J.-G. Zhang, C.-M. Wang, Nano Lett. 2015, 15, 514.

[254] D. R. Baer, C. F. Windisch, M. H. Engelhard, M. J. Danielson, R. H. Jones, J. S. Vetrano, J. Vac. Sci. Technol. A Vacuum, Surfaces, Film. 2002, 18, 131.

[255] A. Dankeaw, F. Gualandris, R. H. Silva, K. Norrman, M. Gudik-Sørensen, K. K. Hansen, B. Ksapabutr, V. Esposito, D. Marani, New J. Chem. 2018, 42, 9501.

[256] G. Arora, D. S. Aidhy, J. Mater. Chem. A 2017, 5, 4026.

[257] A. Borodin, M. Reichling, Phys. Chem. Chem. Phys. 2011, 13, 15442.

[258] M. Li, W. Hebenstreit, U. Diebold, Surf. Sci. 1998, 414, L951.

[259] J. Wang, R. Chen, L. Xiang, S. Komarneni, Ceram. Int. 2018, 44, 7357.

[260] F. Lopez Gejo, A. S. Foster, R. M. Nieminen, A. L. Shluger, V. B. Sulimov, Phys. Rev. B - Condens. Matter Mater. Phys. 2001, 64, 1.

[261] J.-P. Crocombette, Phys. Chem. Miner. 1999, 27, 138.

[262] N.-W. Lee, K. R. Yoon, J.-Y. Lee, Y. Park, S.-J. Pyo, G.-Y. Kim, D.-H. Ha, W.-H. Ryu, ACS Appl. Energy Mater. 2019, 2, 3513.

[263] K. P. McKenna, F. Hofer, D. Gilks, V. K. Lazarov, C. Chen, Z. Wang, Y. Ikuhara, Nat. Commun. 2014, 5, 1 . 
[264] M. A. Langell, N. R. Cameron, Surf. Sci. 1987, 185, 105.

[265] N. M. Sammes, G. A. Tompsett, H. Näfe, F. Aldinger, J. Eur. Ceram. Soc. 1999, 19, 1801.

[266] V. Esposito, D. W. Ni, Z. He, W. Zhang, A. S. Prasad, J. A. Glasscock, C. Chatzichristodoulou, S. Ramousse, A. Kaiser, Acta Mater. 2013, 61, 6290.

[267] V. Esposito, M. Søgaard, P. V. Hendriksen, Solid State Ionics 2012, 227, 46.

[268] D. Samal, G. Koster, J. Mater. Res. 2015, 30, 463.

[269] J. Chakhalian, A. J. Millis, J. Rondinelli, Nat. Mater. 2012, 11, 92.

[270] J. Maier, Nat. Mater. 2005, 4, 805.

[271] J. A. Wang, R. Limas-Ballesteros, T. López, A. Moreno, R. Gómez, O. Novaro, X. Bokhimi, J. Phys. Chem. B 2001, 105, 9692.

[272] X. H. Wang, J. G. Li, H. Kamiyama, M. Katada, N. Ohashi, Y. Moriyoshi, T. Ishigaki, J. Am. Chem. Soc. 2005, 127, 10982.

[273] U. Diebold, Surf. Sci. Rep. 2003, 48, 53.

[274] K. Chen, X. Pei, L. Tang, H. Cheng, Z. Li, C. Li, X. Zhang, L. An, J. Eur. Ceram. Soc. 2018, 38, 4161.

[275] J. Gild, M. Samiee, J. L. Braun, T. Harrington, H. Vega, P. E. Hopkins, K. Vecchio, J. Luo, J. Eur. Ceram. Soc. 2018, 38, 3578.

[276] V. Schuler, F. J. Bonilla, D. Demaille, A. Coati, A. Vlad, Y. Garreau, M. SauvageSimkin, A. Novikova, E. Fonda, S. Hidki, V. Etgens, F. Vidal, Y. Zheng, Nano Res. 2015, 8, 1964.

[277] S. Sanna, V. Esposito, J. W. Andreasen, J. Hjelm, W. Zhang, T. Kasama, S. B. Simonsen, M. Christensen, S. Linderoth, N. Pryds, Nat. Mater. 2015, 14, 500.

[278] S. Sanna, V. Esposito, M. Christensen, N. Pryds, APL Mater. 2016, 4, 121101.

[279] D. Gioacchino, A. Marcelli, A. Puri, C. Zou, L. Fan, U. Zeitler, A. Bianconi, Condens. Matter 2017, 2, 10. 
[280] Y. Wan, Y. Li, Q. Li, W. Zhou, Q. Zheng, X. Wu, C. Xu, B. Zhu, D. Lin, J. Am. Ceram. Soc. 2014, 97, 1809.

[281] L. K. Dash, N. Vast, P. Baranek, M. C. Cheynet, L. Reining, Phys. Rev. B - Condens. Matter Mater. Phys. 2004, 70, 1.

[282] S. Sanna, V. Esposito, C. Graves, J. Hjelm, J. W. Andreasen, N. Pryds, Solid State Ionics 2014, 266, 13.

[283] V. Esposito, E. Traversa, E. D. Wachsman, J. Electrochem. Soc. 2005, 152, A2300.

[284] V. Esposito, B. H. Luong, E. Di Bartolomeo, E. D. Wachsman, E. Traversa, J. Electrochem. Soc. 2006, 153, A2232.

[285] C.-C. Huang, K.-Z. Fung, J. Mater. Res. 2003, 18, 2624.

[286] R. Ramesh, V. G. Keramidas, Annu. Rev. Mater. Sci. 1995, 25, 647.

[287] N. Sata, K. Eberman, K. Eberl, J. Maier, Nature 2000, 408, 946.

[288] X. Wang, T. Wang, J. Borovilas, X. He, S. Du, Y. Yang, Nano Res. 2019, 12, DOI 10.1007/s12274-019-2392-x.

[289] L. Yan, H. Niu, C. A. Bridges, P. A. Marshall, J. Hadermann, G. van Tendeloo, P. R. Chalker, M. J. Rosseinsky, Angew. Chemie Int. Ed. 2007, 46, 4539.

[290] J. Schoonman, Solid State Ionics 2003, 157, 319.

[291] D. W. Ni, V. Esposito, J. Power Sources 2014, 266, 393.

[292] F. Teocoli, D. W. Ni, S. Sanna, K. Thydén, F. C. Fonseca, V. Esposito, J. Mater. Chem. A 2015, 3, 17135.

[293] F. Teocoli, D. W. Ni, K. Brodersen, S. P. V. Foghmoes, S. Ramousse, V. Esposito, J. Mater. Sci. 2014, 49, 5324.

[294] L. Dos Santos-Gómez, S. Sanna, P. Norby, N. Pryds, E. R. Losilla, D. Marrero-López, V. Esposito, Nanoscale 2019, 11, 2916.

[295] R. K. Vasudevan, K. Choudhary, A. Mehta, R. Smith, G. Kusne, F. Tavazza, L. Vlcek, M. Ziatdinov, S. V. Kalinin, J. Hattrick-Simpers, MRS Commun. 2019, 9, 821. 
[296] Z. Lan, T. Vegge, I. E. Castelli, n.d., DOI 10.26434/chemrxiv.10119230.v1.

[297] S. Ninova, U. Aschauer, J. Mater. Chem. A 2017, 5, 11040.

[298] A. S. Barnard, Reports Prog. Phys. 2010, 73, DOI 10.1088/0034-4885/73/8/086502.

[299] V. Esposito, A. Kabir, M. Rosa, N. Van Nong, T. S. Rodrigues, L. N. Rodrigues, M. F. S. Machado, L. P. R. Moraes, D. Marani, F. C. Fonseca, CrystEngComm 2019, 4025.

[300] S. Beschnitt, T. Zacherle, R. A. De Souza, J. Phys. Chem. C 2015, 119, 27307.

[301] Y. Dong, L. Qi, J. Li, I.-W. Chen, 2018, 43.

[302] M. Wang, A. Navrotsky, J. Solid State Chem. 2005, 178, 1230.

[303] J. L. M. Rupp, Solid State Ionics 2012, 207, 1.

[304] A. Hjorth Larsen, J. Jørgen Mortensen, J. Blomqvist, I. E. Castelli, R. Christensen, M. Dułak, J. Friis, M. N. Groves, B. Hammer, C. Hargus, E. D. Hermes, P. C. Jennings, P. Bjerre Jensen, J. Kermode, J. R. Kitchin, E. Leonhard Kolsbjerg, J. Kubal, K. Kaasbjerg, S. Lysgaard, J. Bergmann Maronsson, T. Maxson, T. Olsen, L. Pastewka, A. Peterson, C. Rostgaard, J. Schiøtz, O. Schütt, M. Strange, K. S. Thygesen, T. Vegge, L. Vilhelmsen, M. Walter, Z. Zeng, K. W. Jacobsen, J. Phys. Condens. Matter 2017, 29, 273002.

[305] J. J. Mortensen, L. B. Hansen, K. W. Jacobsen, Phys. Rev. B 2005, 71, 035109.

[306] J. Enkovaara, C. Rostgaard, J. J. Mortensen, J. Chen, M. Dułak, L. Ferrighi, J. Gavnholt, C. Glinsvad, V. Haikola, H. A. Hansen, H. H. Kristoffersen, M. Kuisma, A. H. Larsen, L. Lehtovaara, M. Ljungberg, O. Lopez-Acevedo, P. G. Moses, J. Ojanen, T. Olsen, V. Petzold, N. A. Romero, J. Stausholm-Møller, M. Strange, G. A. Tritsaris, M. Vanin, M. Walter, B. Hammer, H. Häkkinen, G. K. H. Madsen, R. M. Nieminen, J. K. Nørskov, M. Puska, T. T. Rantala, J. Schiøtz, K. S. Thygesen, K. W. Jacobsen, J. Phys. Condens. Matter 2010, 22, 253202.

[307] J. P. Perdew, A. Ruzsinszky, G. I. Csonka, O. A. Vydrov, G. E. Scuseria, L. A. Constantin, X. Zhou, K. Burke, Phys. Rev. Lett. 2008, 100, 136406. 
[308] G. Kresse, J. Furthmüller, Phys. Rev. B 1996, 54, 11169.

[309] A. Jain, S. P. Ong, G. Hautier, W. Chen, W. D. Richards, S. Dacek, S. Cholia, D.

Gunter, D. Skinner, G. Ceder, K. A. Persson, APL Mater. 2013, 1, DOI

10.1063/1.4812323.

[310] K. Momma, F. Izumi, J. Appl. Crystallogr. 2011, 44, 1272.

[311] Y. Chiang, D. P. Birnie, W. D. Kingery, Physical Ceramics, J. Wiley, 1997.

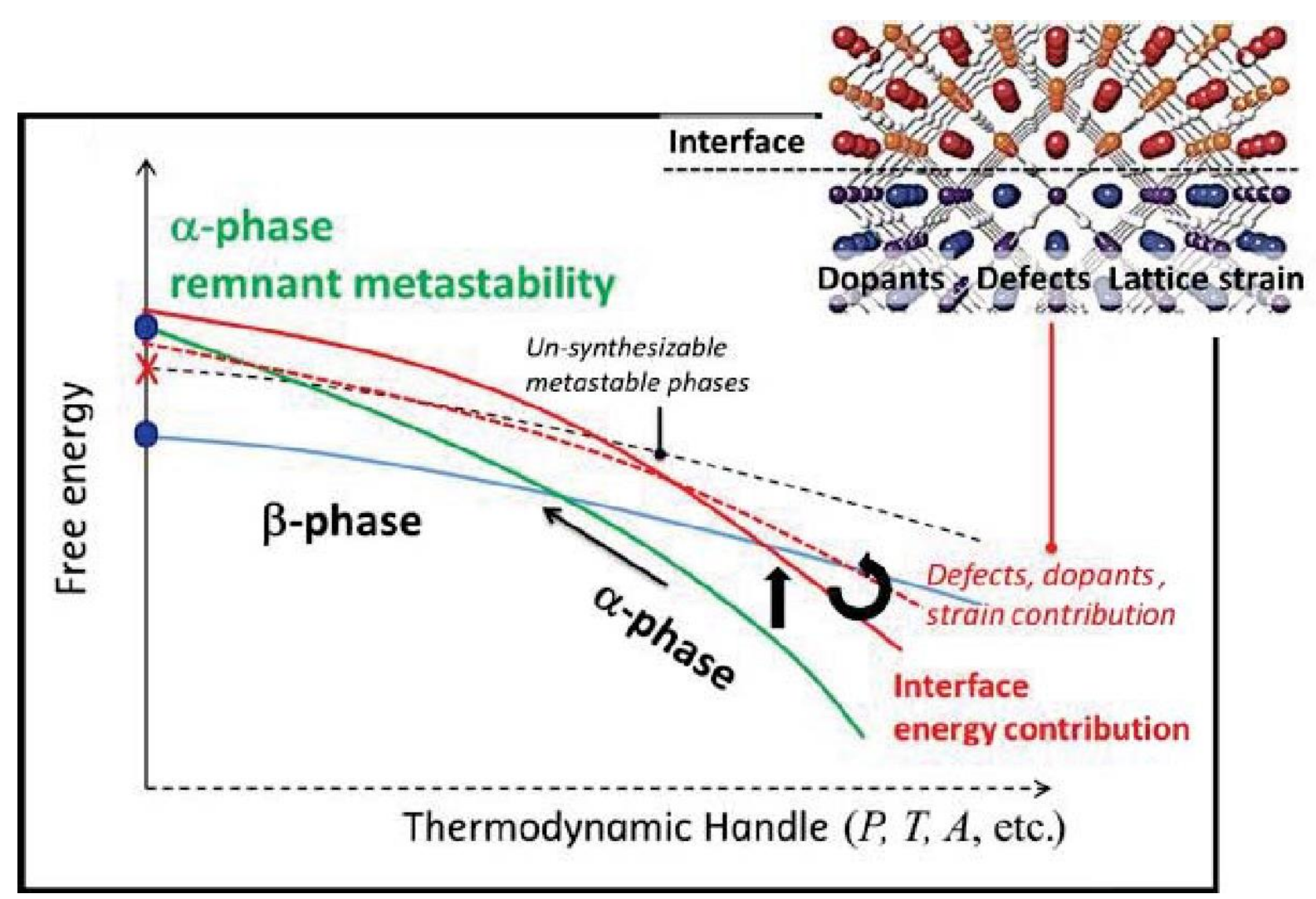

Figure 1. Schematic representation of possible paths towards metastability in interface-based materials; Additional interface energy contributions, e.g., introduced by defects, dopants and lattice strain, can deviate the formation of Gibbs' phase from $\alpha$ to $\beta$ by trapping an already existing metastable $\alpha$-phase, rather other possible phases (figure adapted from Sun et al. ${ }^{[15]}$ ). 
WILEY-VCH

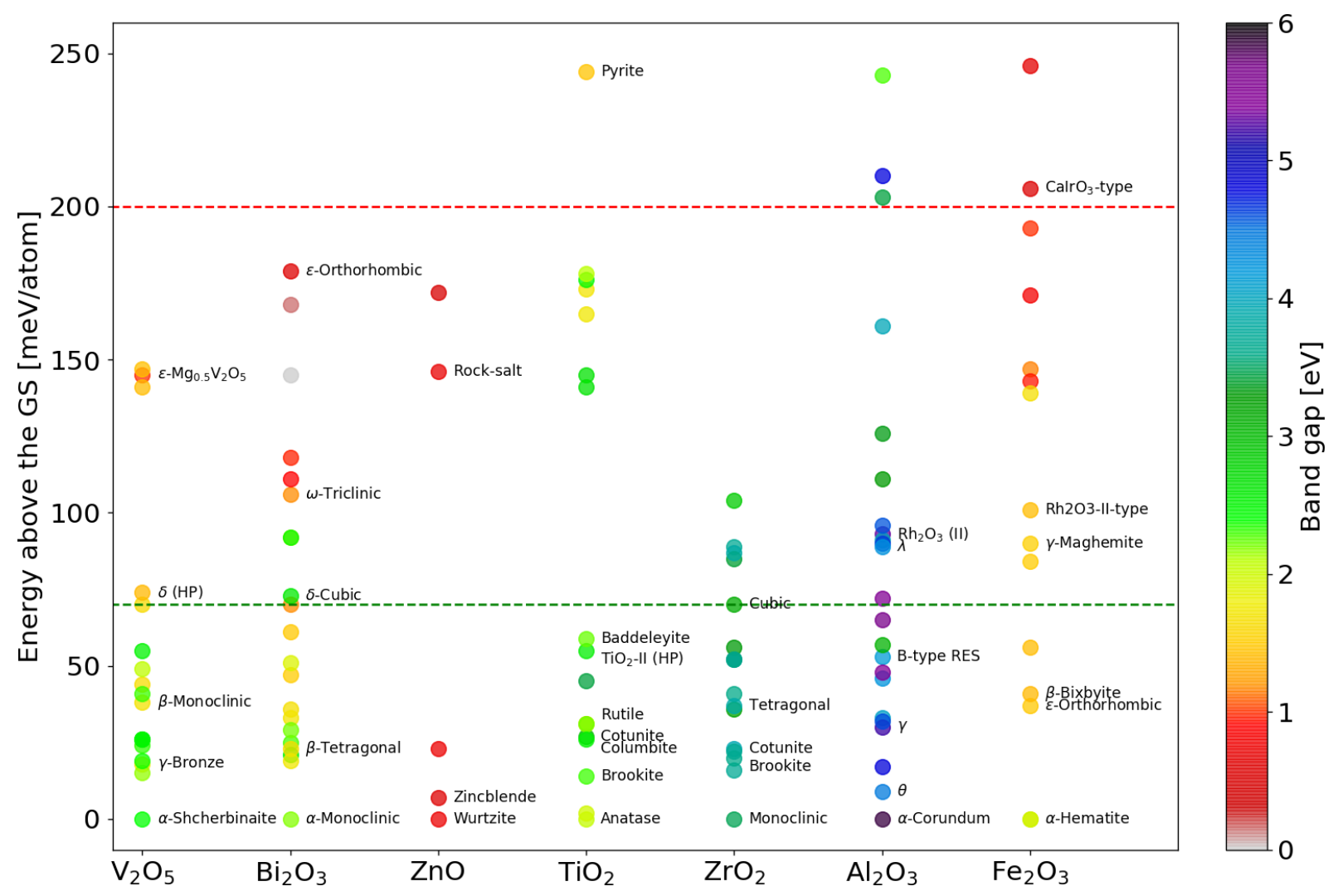

Figure 2. Polymorphic structures of common binary oxides. The energy difference compared to the ground state structure is visible on the y-axis and the band gaps are indicated by the color bar. Names of existing polymorphs are listed. A soft and hard limit for the synthesizability of polymorphic structures is drawn with green $(70 \mathrm{meV} /$ atom $)$ and red (200 meV/atom) lines ${ }^{[15]}$. Data obtained from the Materials Project database ${ }^{[34]}$, calculated at the DFT-GGA+U level ${ }^{[309]}$. 


\section{WILEY-VCH}
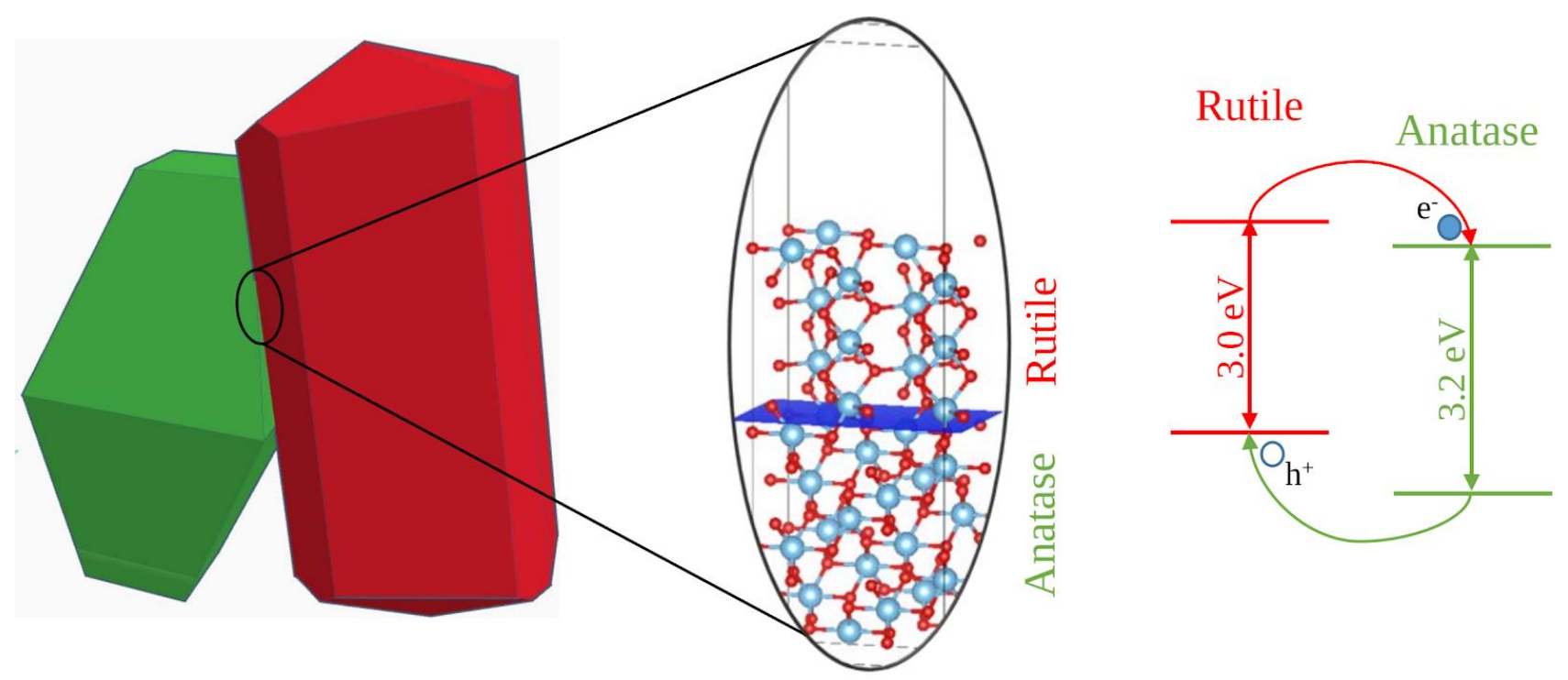

Figure 3. Example of coexistence of stable and metastable phases in $\mathrm{TiO}_{2}$, leading to p-n junction suitable for photoelectric applications.

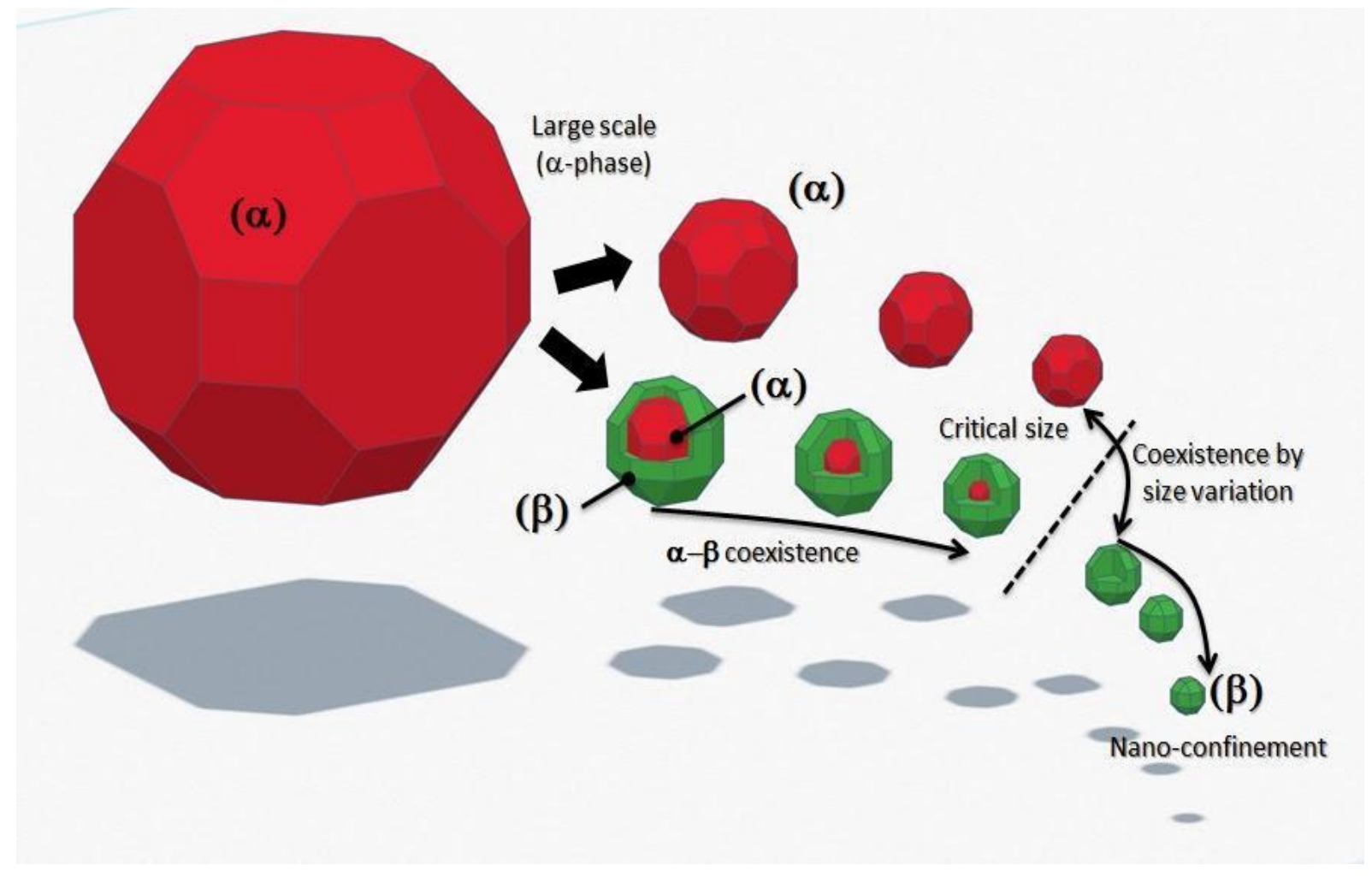

Figure 4. Examples of critical size and of coexistence in nanomaterials: two cases illustrated show either a phase change at the critical size (red to green crystals) of a coexistence of the phases with nucleation of the different phases at the surface and the core of the crystals. 


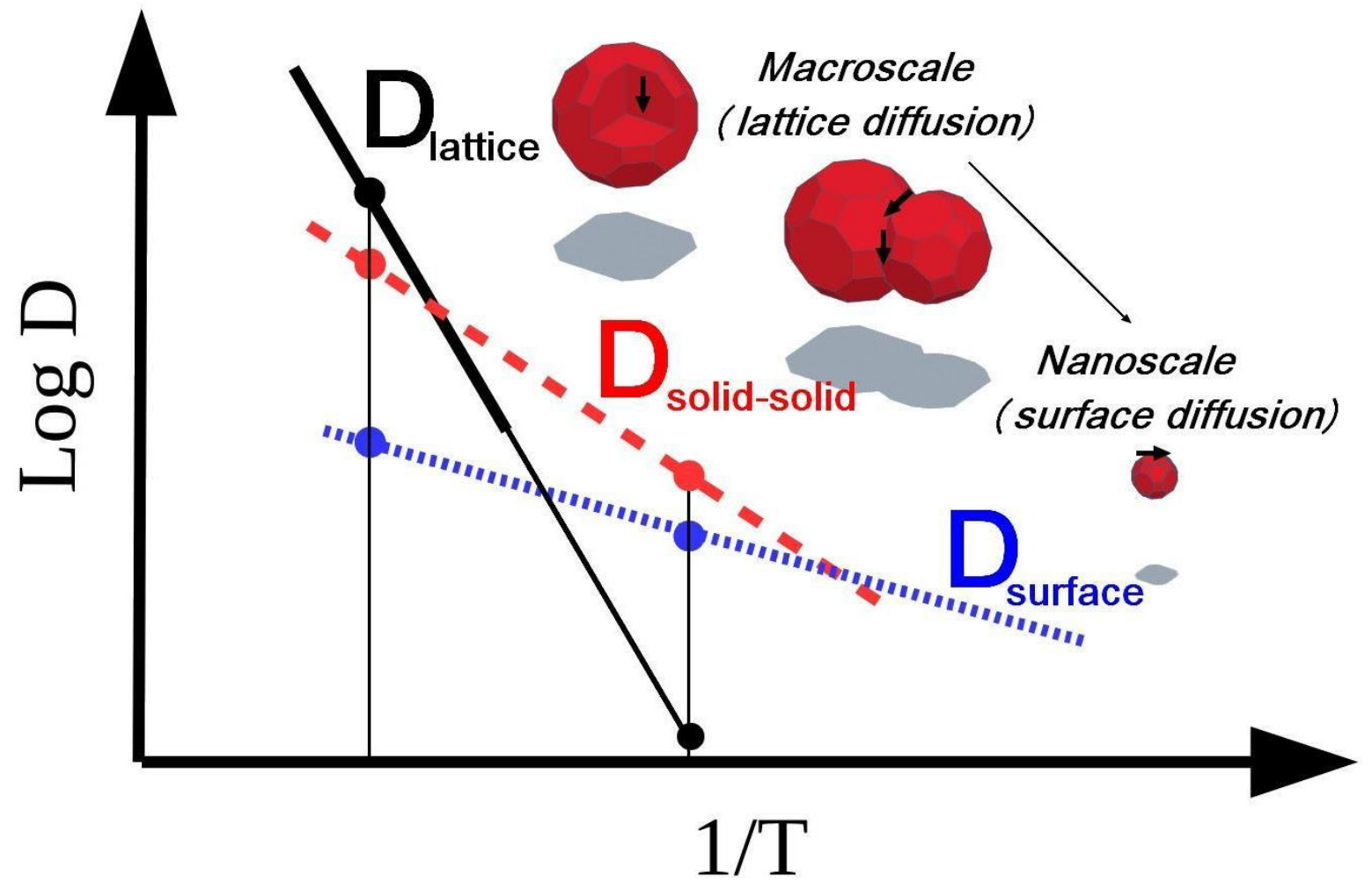

Figure 5. Schematic representation of thermal diffusivity mechanisms in metal oxides for lattice, solid-solid interface and free surface of particles. 


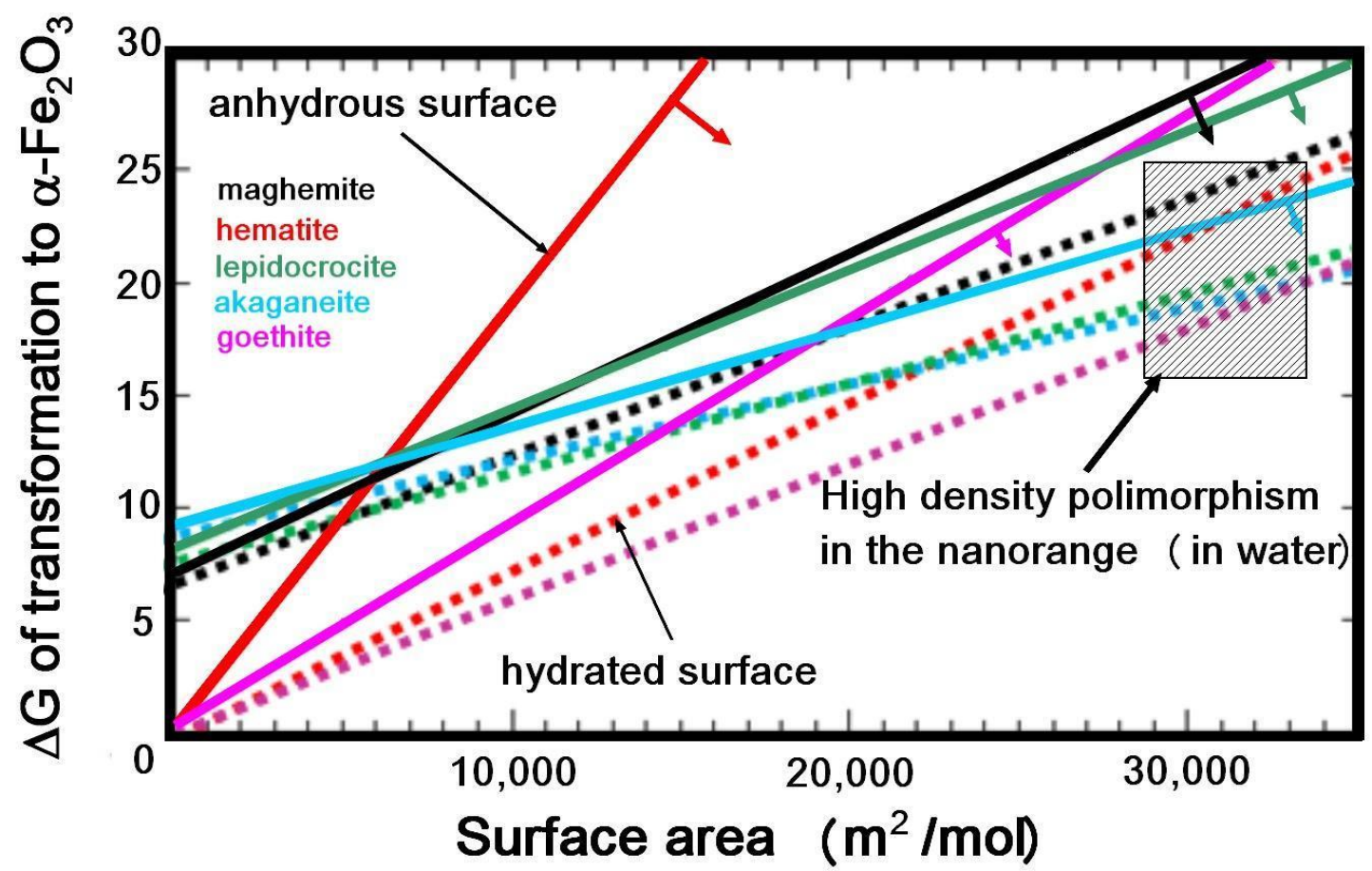

Figure 6. Energetic competition in forming $\alpha-\mathrm{Fe}_{2} \mathrm{O}_{3}$ between phases in iron oxides for both anhydrous (solid lines) and hydrated surfaces (dashed line) expressed as a function of the specific surface area at the nanosize (figure adapted from reported by Navrotsky et al. ${ }^{[151]}$ ).
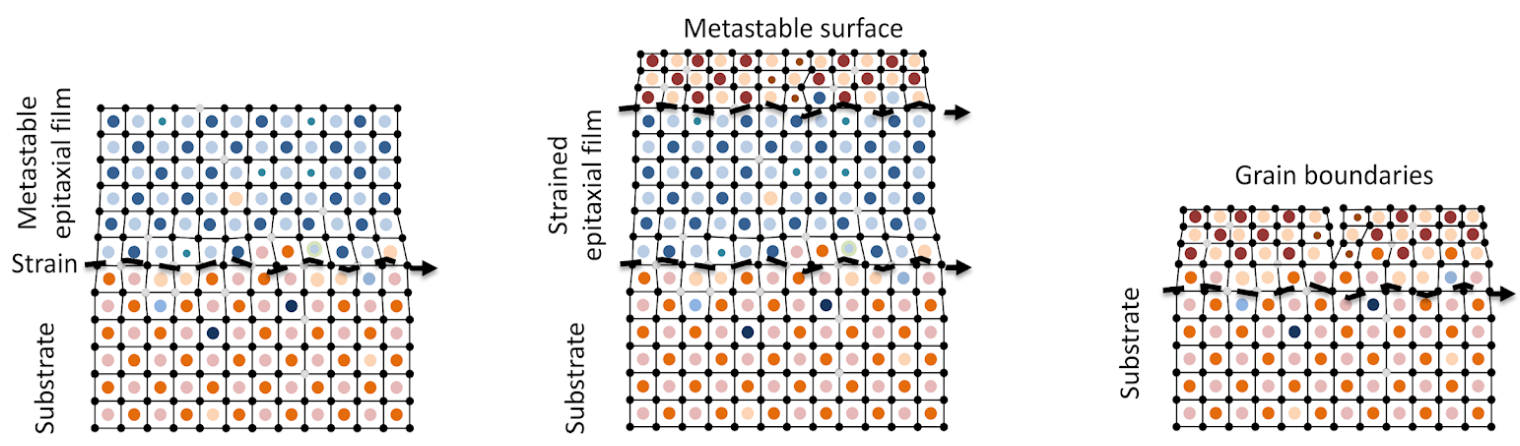

\section{Strain}

Moderate

Breaking point

Figure 7. Schematic representation of strain effects on interface and free interface the case of coherent and semi-coherent lattices. 


\section{WILEY-VCH}

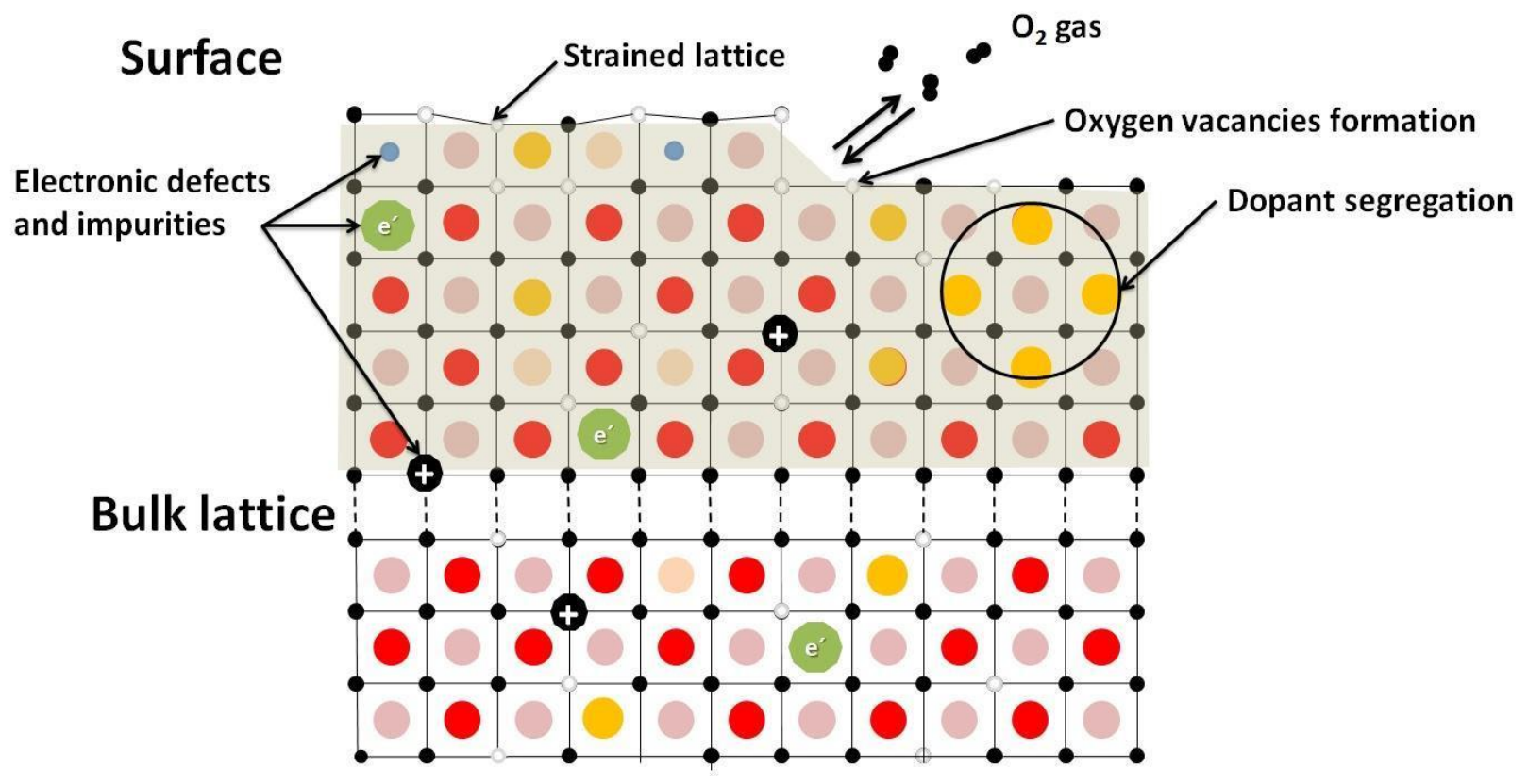

Figure 8. Schematic representation of the typical features registered at metal oxide surface are oxygen vacancies by oxygen gas desorption, strained lattice, dopant, electronic defects and impurities segregation.

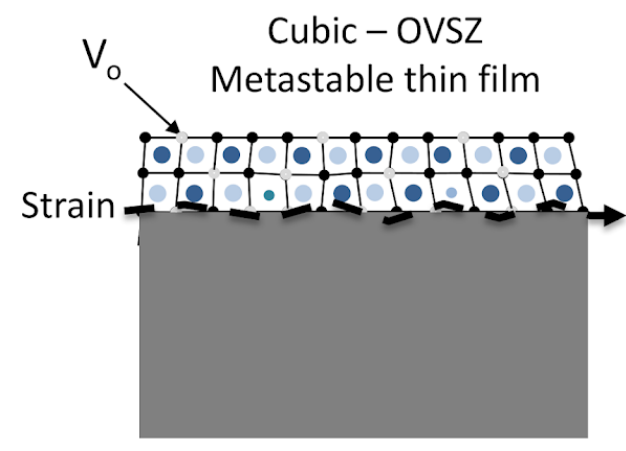

Si Substrate
Stable Monoclinic/Tetragonal $\mathrm{ZrO}_{2}$

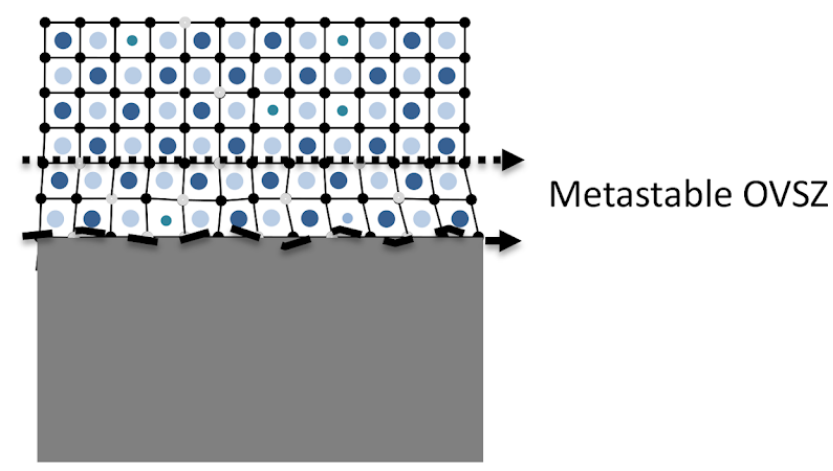

Si Substrate

Figure 9. schematic representation of the combined effect of strain, defects and disorder in oxygen vacancy stabilized zirconia OVS $\mathrm{ZrO}_{2}$ deposited on silicon and other substrates as reported in Ref. ${ }^{[225]}$. 


\section{WILEY-VCH}

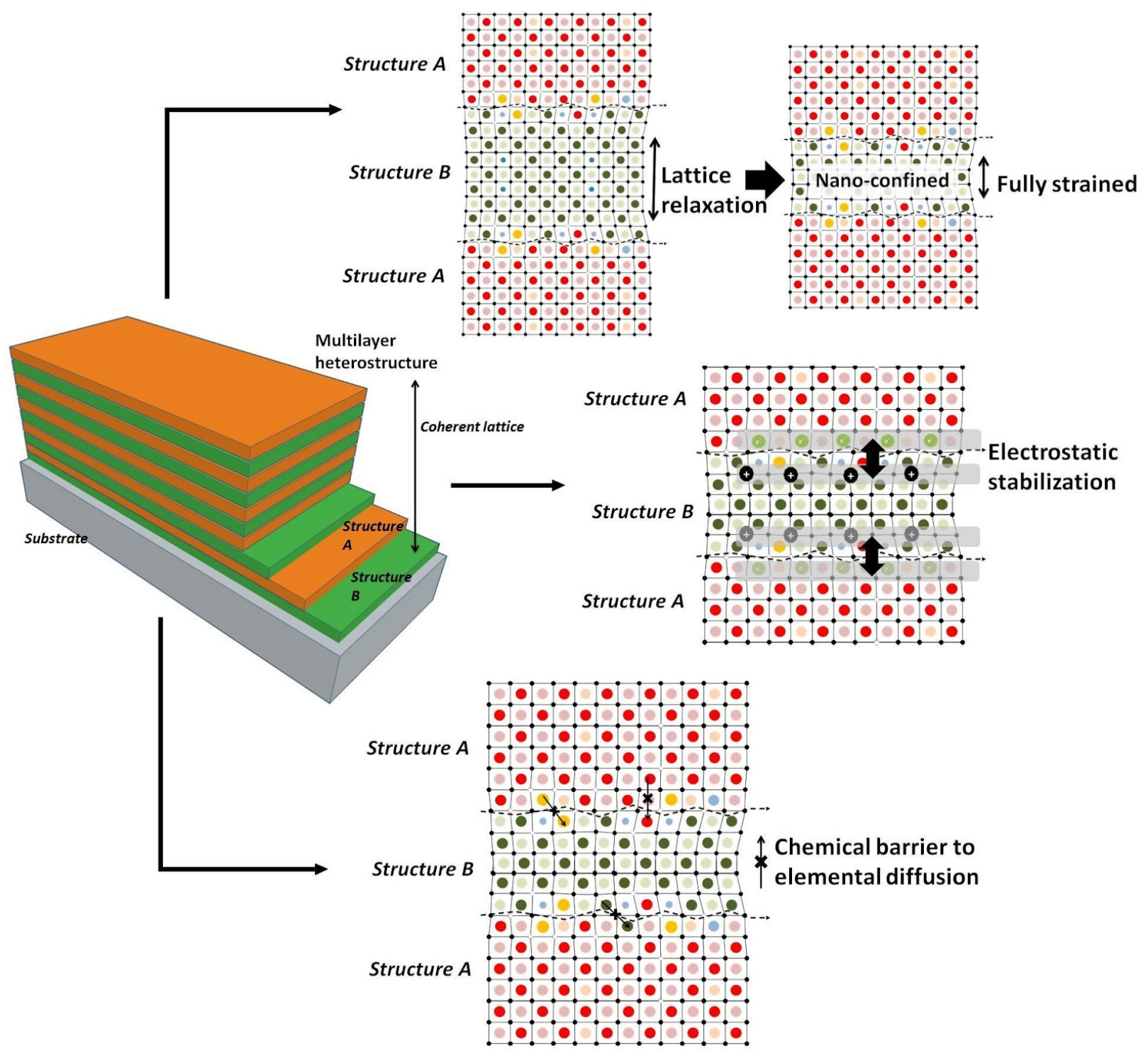

Figure 10. Schematically resume the effects observed in multilayer heterostructures for defective metal oxides in nanoconfined coherent epitaxial thin films. 
WILEY-VCH

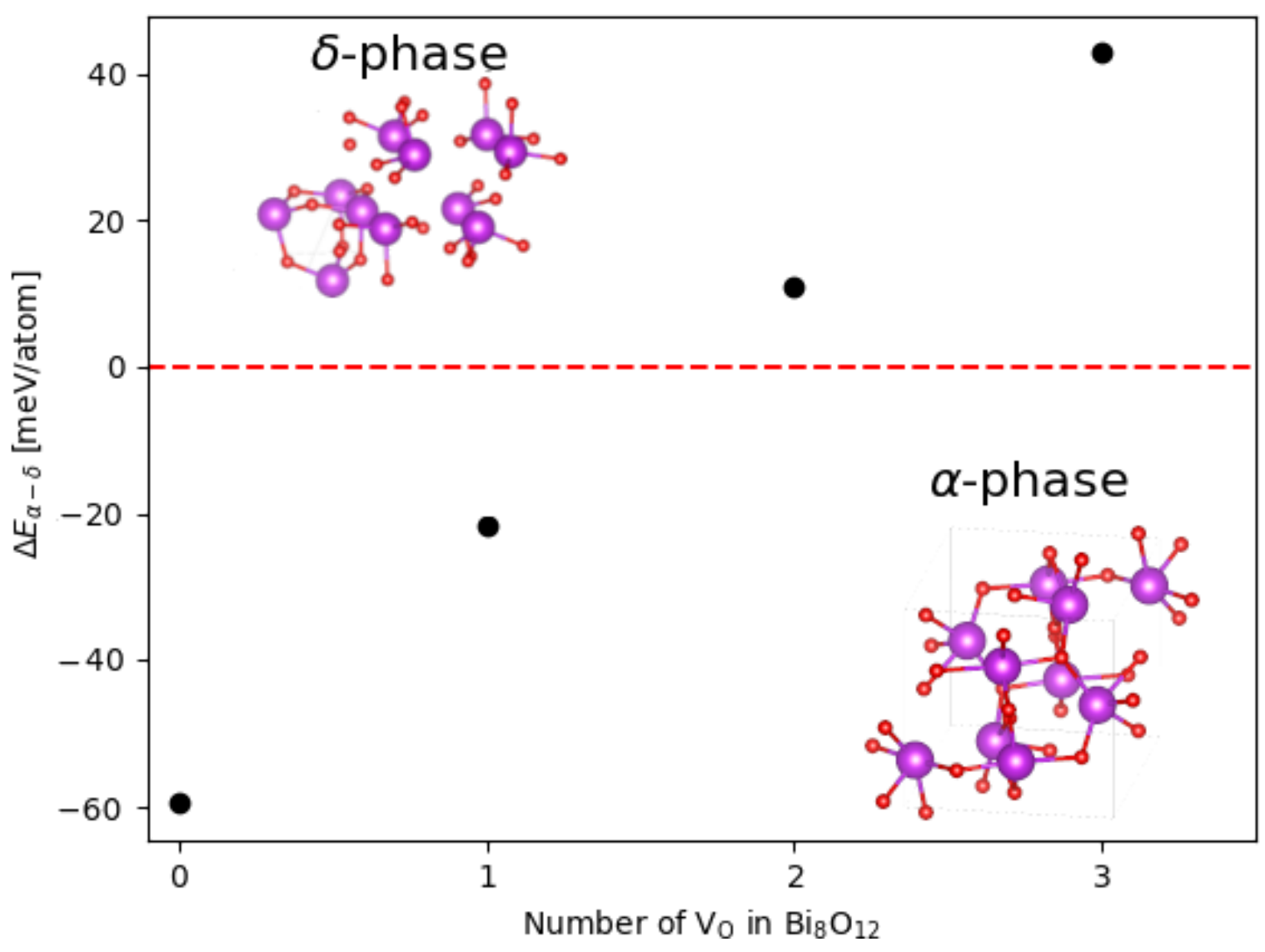

Figure 11. Energy difference between the $\alpha$ - and $\delta$-phase $\left(\Delta \mathrm{E}_{\alpha-\delta}\right)$ of $\mathrm{Bi}_{2} \mathrm{O}_{3}$ as a function of the number oxygen vacancies calculated in a $2 \times 2 \times 1$ supercell. The $\delta$-phase becomes the energetically most favourable phase at high vacancy concentrations.

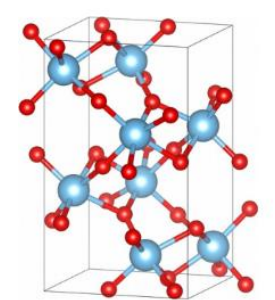

Brookite

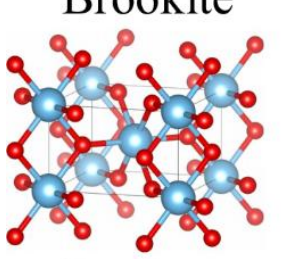

Rutile

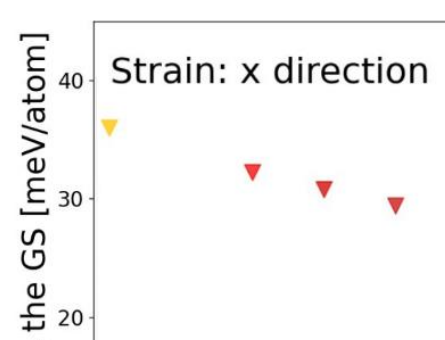

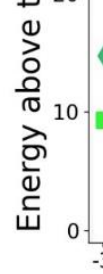

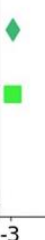
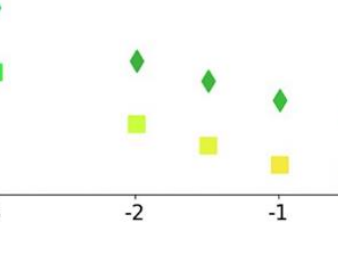

Strain [\%]

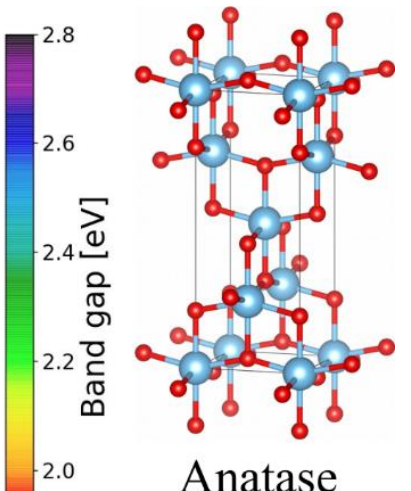

Figure 12. Energy above the ground state (GS) for titania anatase, brookite, and rutile under strain in the x-direction. The band gap is indicated by the color bar. 


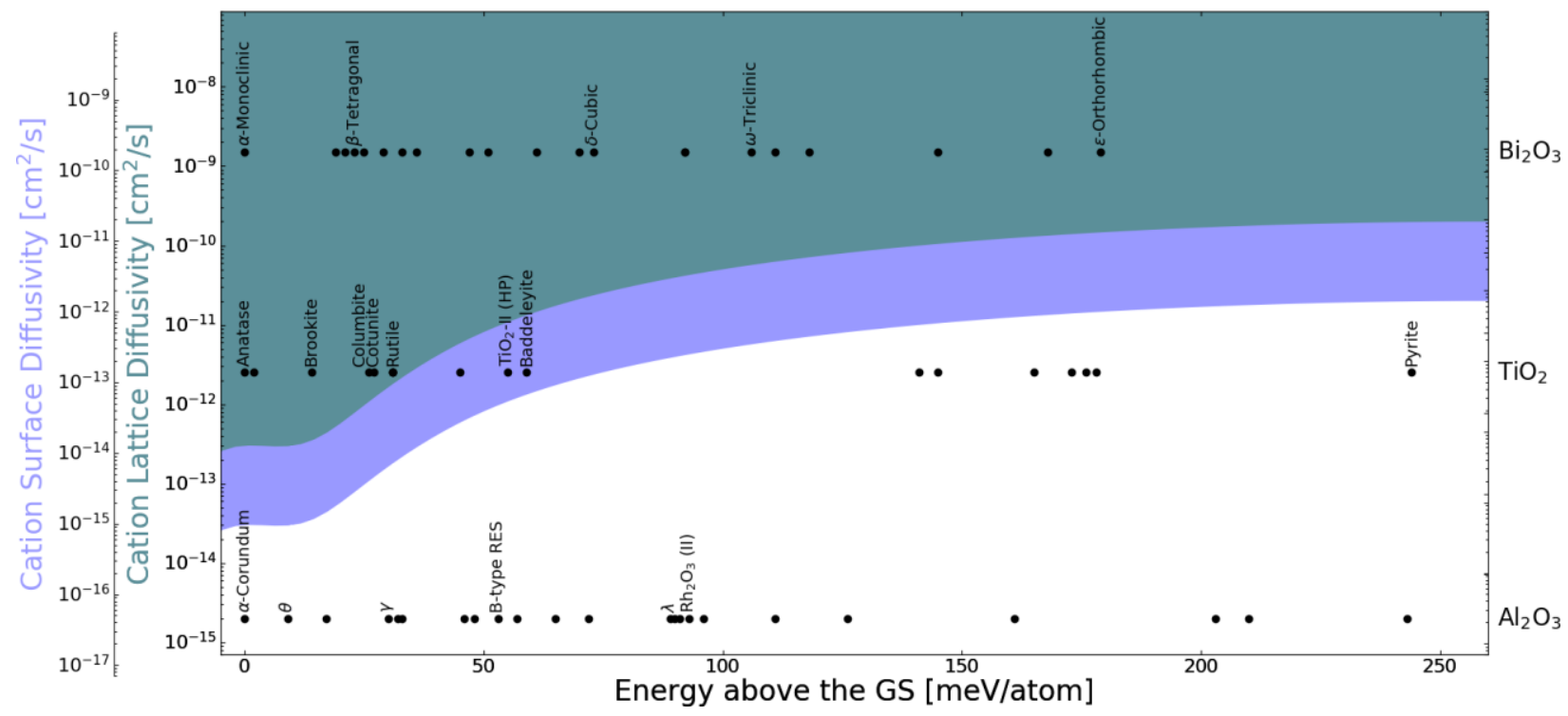

Figure 13. The cation diffusion (y-axis, data from Refs. ${ }^{[217,311]}$ ) plays an important role in the coexistence of polymorphs, whose energy above the ground state is plotted in the $\mathrm{x}$-axis (data from the Materials Project $\left.{ }^{[34]}\right)$. The green area indicates the region where cation diffusion in the lattice would be able to drive a change in the ground state prototype. Since the cation diffusion on the surface is larger than in the lattice, it is possible to extend the area where cation diffusion is the driving force for transition in the ground state (light blue area).

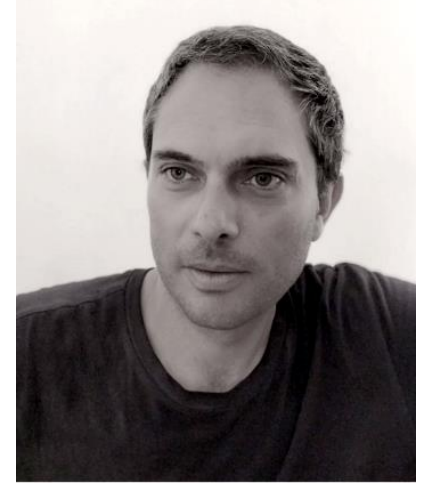

Vincenzo Esposito is a full professor at Technical University of Denmark, Department of Energy Conversion and Storage (DTU Energy). His research interest is primarily functional inorganic nano-materials and processing for energy and environmental technologies. He developed his career at Ris $\emptyset$ National Laboratory for Sustainable Energy, University of RomeTor Vergata, University of Florida, and at the Nuclear and Energy Research Institute (IPEN). He has been working on functional metal oxides for more than 15 years being especially involved in several research activities and innovative projects on advanced processing and 
materials nano-engineering. He is co-author of several scientific papers on the topic $(>100)$, including high impact journals in material science, such as Nature Materials, Adv. Funct Mater, Small, Journal of Material Chemistry A, etc.

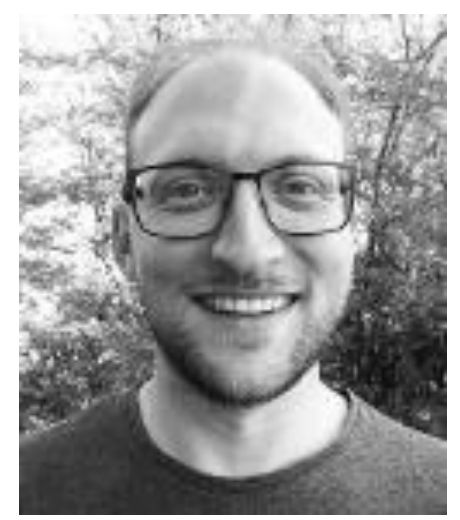

Ivano E. Castelli is an assistant professor at the Technical University of Denmark, Department of Energy Conversion and Storage (DTU Energy). Ivano got his PhD in 2013, in the group of Prof. Jacobsen (DTU Physics). He also worked as a EPFL Fellow in the group of Prof. Marzari (EPFL, Switzerland) and as a postdoc researcher in Prof. Rossmeisl group (University of Copenhagen, Denmark). His research focuses on understanding materials' properties and on discovering novel materials, using quantum mechanical simulations, mostly in the framework of Density Functional Theory. His main interests include design of perovskites and materials with reduced dimensionality for energy applications, as well as modeling solid/electrolyte and solid/solid interfaces in battery devices. 
Evidence of metastability in nanomaterials and heterostructures of polymorphic metal oxides that are confined by interfaces is disclosed. Developing a new generation of nanoengineered phases, frozen in metastable states, can advance us towards new scenarios in the field of condensed matter physics while impacting technology through enhanced or even novel functionalities in advanced materials.

Keywords: Nanostructures, Nanoparticles, Metal oxides, Interface, Surface, Metastability, Defects, Ionics

Vincenzo Esposito* and Ivano E. Castelli. Corresponding Author*

\section{Metastability at defective metal oxide interfaces and nanoconfined structures}

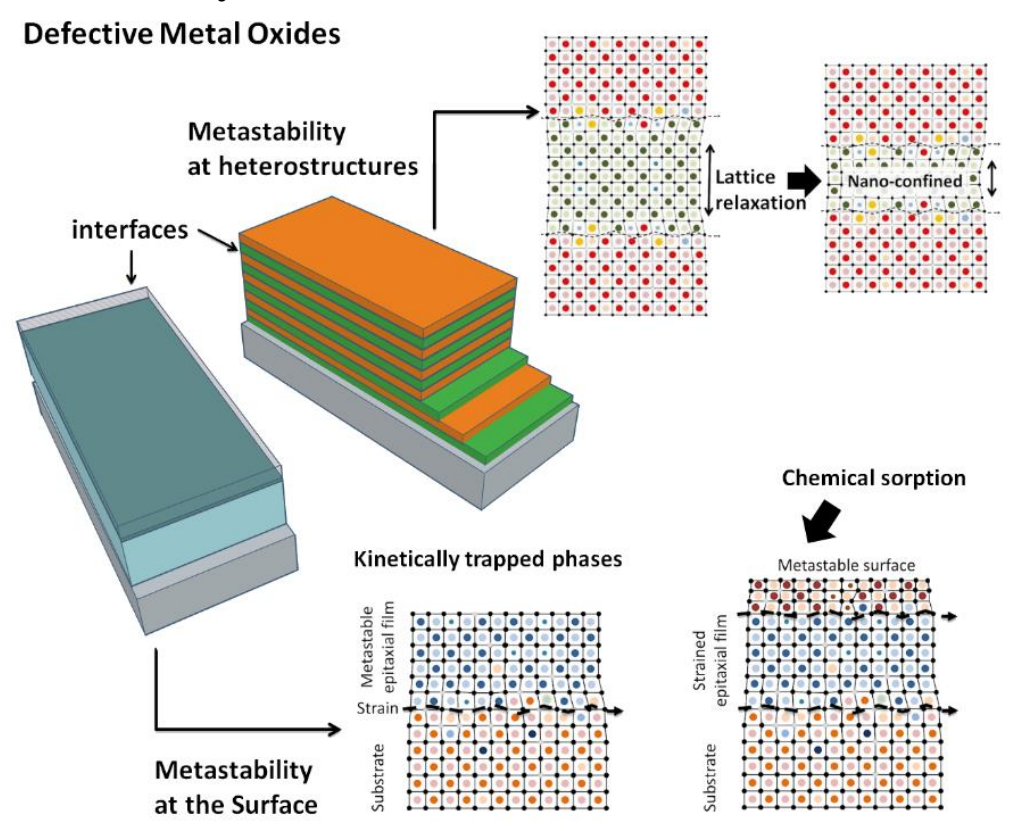

Copyright WILEY-VCH Verlag GmbH \& Co. KGaA, 69469 Weinheim, Germany, 2016. 